\title{
Career Fire Apparatus Operator Dies after Falling Down an Unsecured Elevator Shaft at a 5-Story Residential Structure - Ohio
}

\section{Executive Summary}

On March 26, 2015, a 54-year-old male career fire apparatus operator (FAO) died after falling down an unsecured elevator shaft. The FAO was assigned to Heavy Rescue 14, which responded on the second alarm to a working fire on the second floor of a five-story residential apartment building. The four person Heavy Rescue 14 was assigned to search for occupants on the fifth floor. The crew advanced to the fifth floor and began searching apartments. The FAO was the last Heavy Rescue 14 crew member to enter the fifth floor and became separated from the rest of his crew. Visibility was limited to about 5 feet due to moderate smoke. The floor had a centrally located hallway providing access to eight residential apartments. A hydraulic elevator located near the center of the building provided access to each floor. The elevator was accessible on each floor by an outward swinging metal door that included a locking mechanism at the top left corner designed to keep the door closed until the elevator car reached that floor. The locking mechanism on the fifth floor was not functioning properly on this date. Three members of Heavy Rescue 14 observed that the door could

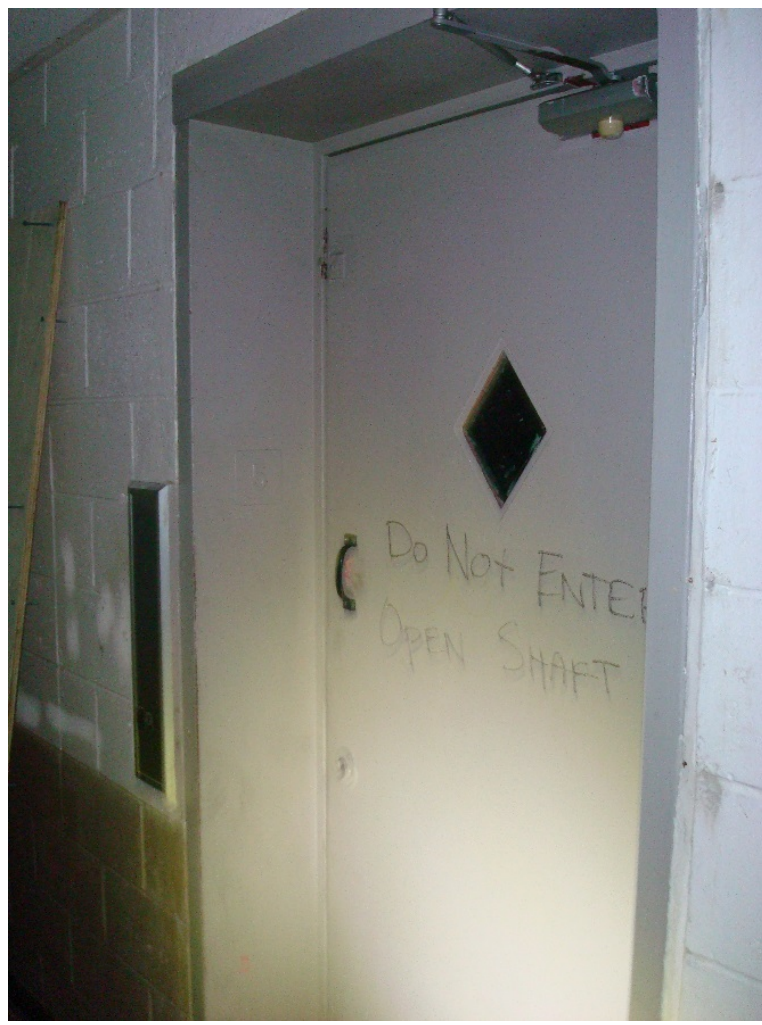
be easily opened. They reported this finding to the search and rescue operations chief (District Chief 3) who was on the fifth floor. A fire fighter used a permanent marker to write "Do Not Enter. Open Shaft" on the elevator door. A short time later, the

Fifth floor elevator hoistway door. Note warning written on door by Rescue 14 crew member while searching the fifth floor.

(Photo NIOSH) FAO, believed to be looking for his crew, opened the elevator door and fell approximately 24 feet down the elevator shaft, striking the top rear edge of the elevator car and became stuck between the rear of the elevator car and the elevator shaft wall. The acting officer on Heavy Rescue 14 radioed a Mayday after realizing the FAO had fallen down the elevator shaft. Extrication efforts took approximately 14 minutes from the time of the Mayday. The FAO was pronounced dead at a local hospital. Three fire fighters received minor injuries extinguishing the fire. The fire department successfully rescued 21 civilian occupants from their apartments during the incident.

\section{Contributing Factors}

- Breakdown in crew integrity 


\section{Career Fire Apparatus Operator Dies after Falling Down an Unsecured Elevator Shaft at a 5-Story Residential Apartment Building - Ohio}

- Unsecured and unguarded elevator hoistway door

- Poor visibility due to moderate smoke conditions

- Delay in getting water onto the fire burning in a second-floor apartment

- Acting officers in several key positions

- No standpipe or sprinkler system within the residential apartment building.

\section{Key Recommendations}

- Ensure that crew integrity is properly maintained by sight, voice or radio contact when operating in an immediately dangerous to life and health (IDLH) atmosphere.

- Train and empower all fire fighters to report unsafe conditions to Incident Command.

- Ensure that appropriate staffing levels are available on scene to accomplish fireground tasks and be available for unexpected emergencies.

- Review standard operating procedures used to account for all fire fighters and first responders assigned to an incident.

- Ensure that interior attack crews always enter a hazardous environment with a charged hoseline.

- Integrate current fire behavior research findings developed by the National Institute of Standards and Technology (NIST) and Underwriter's Laboratories (UL) into operational procedures by developing or updating standard operating procedures, conducting live fire training, and revising fireground tactics.

- Consider ways to block open shafts and other fall hazards.

Additionally, state, local, and municipal governments, building owners and authorities having jurisdiction should:

- $\quad$ Consider requiring sprinkler systems be installed in multi-family housing units.

The National Institute for Occupational Safety and Health (NIOSH), an institute within the Centers for Disease Control and Prevention (CDC), is the federal agency responsible for conducting research and making recommendations for the prevention of work-related injury and illness. In 1998, Congress appropriated funds to NIOSH to conduct a fire fighter initiative that resulted in the NIOSH "Fire Fighter Fatality Investigation and Prevention Program" which examines line-of-duty-deaths or on duty deaths of fire fighters to assist fire departments, fire fighters, the fire service and others to prevent similar fire fighter deaths in the future. The agency does not enforce compliance with State or Federal occupational safety and health standards and does not determine fault or assign blame. Participation of fire departments and individuals in NIOSH investigations is voluntary. Under its program, NIOSH investigators interview persons with knowledge of the incident who agree to be interviewed and review available records to develop a description of the conditions and circumstances leading to the death(s). Interviewees are not asked to sign swom statements and interviews are not recorded. The agency's reports do not name the victim, the fire department or those interviewed. The NIOSH report's summary of the conditions and circumstances surrounding the fatality is intended to provide context to the agency's recommendations and is not intended to be definitive for purposes of determining any claim or benefit.

For further information, visit the program website at www.cdc.gov/niosh/fire or call toll free 1-800-CDC-INFO (1-800-232-4636). 


\section{Career Fire Apparatus Operator Dies after Falling Down an Unsecured Elevator Shaft at a 5-Story Residential Structure - Ohio}

\section{Introduction}

On March 26, 2015, a 54-year-old male career fire apparatus operator (FAO) fell down an unsecured elevator shaft while searching for occupants on the fifth floor of a five-story residential apartment building. He was pronounced dead at a local hospital later that day. The U.S. Fire Administration notified the National Institute for Occupational Safety and Health (NIOSH) of this incident the same day.

NIOSH investigators worked with fire department representatives over the next several days to determine the best date for conducting this investigation. On April 17-23, 2015, a safety engineer and a general engineer from the NIOSH Fire Fighter Fatality Investigation and Prevention Program traveled to Ohio to investigate this incident. The NIOSH investigators met with representatives of the fire department and the International Association of Fire Fighters local union. The NIOSH investigators obtained and reviewed copies of the fire dispatch and fireground audio records and transcripts, fire department standard operating procedures and guidelines, incident scene photographs, and training records for the FAO. The NIOSH investigators visited and photographed the incident scene and interviewed fire officers and fire fighters involved in the incident. The NIOSH investigators returned to Ohio on May 07, 2015, to continue interviewing fire department members involved in this incident.

On May 22, 2015, the NIOSH investigators traveled to Pennsylvania to the SCBA manufacturer's facility where representatives of the SCBA manufacturer inspected the self-contained breathing apparatus worn by the FAO at the time of the fall. The SCBA data logger was successfully downloaded and the data retrieved for further analysis during the inspection. Members of the fire department, the IAFF local union, and NIOSH witnessed this inspection. The SCBA was then transported to the NIOSH National Personal Protective Technology Laboratory facility in Morgantown, West Virginia where the SCBA was further tested by representatives of NIOSH NPPTL.

The NIOSH investigators returned to Ohio on June 8, 2015 to witness an elevator inspection at the incident scene. Representatives of the building ownership coordinated the elevator inspection and hired an independent consultant to inspect the elevator. The elevator inspection was witnessed by members of the fire department, the International Association of Fire Fighters local union, representatives from the city’s planning and buildings division and NIOSH.

\section{Fire Department}

At the time of this incident, this career fire department had 840 uniformed members serving a population of approximately 300,000 within an area of about 78 square miles. The city is made up of 52 individual communities. 


\section{Career Fire Apparatus Operator Died After Falling Down an Unsecured Elevator Shaft at a 5-Story Residential Apartment Building - Ohio}

The fire department consists of four separate bureaus: administration, operations, human resources, and fire prevention. Each bureau is headed by an assistant chief who reports directly to the chief of the department.

All fire fighters assigned to the operations bureau are assigned to one of three shift units and work a 24 hour duty shift with 48 hours off. Fire fighters can be assigned to a fire apparatus or a medic unit for the entire 24-hour shift or they can arrange to work split shifts. The fire department currently has 26 engines, 12 ladder trucks, 2 heavy rescue trucks, and 12 medic units. All engines are fully equipped advanced life support (ALS) medic engines. All engines and trucks are staffed by a minimum crew of four with minimum staffing of 193 per shift. Each medic unit is an advanced life support (ALS) unit staffed by a fire fighter/paramedic and a fire fighter/emergency medical technician (EMT).

The city is divided into four districts. Each district is managed by an on-duty district chief. Currently, there are 12 permanent district chiefs and 3 traveling district chiefs. On any shift, one qualified fire captain per shift can step up to serve as an acting district chief. If more than one district chief is absent, the vacancies are filled by permanent district chiefs working overtime shifts as necessary. Each shift has an on-duty shift safety officer. Qualified fire captains can fill in for absent shift safety officers as necessary.

The fire department has written policies and procedures that are available to all department members within their stations. These policies and procedures have been implemented and are enforced. Policies and procedures cover both operational and administrative activities.

The city dispatch center dispatches both fire and police calls. Dispatchers are civilian city employees. Each fire fighter carries a portable radio assigned to a specific apparatus riding position.

The city has a program with procedures in place intended to help identify hazardous buildings within the city. The Code Enforcement Response Team (CERT) is a committee that includes representatives from the fire department, police department, health department, legal department and the city buildings department. The committee is charged with identifying buildings that present hazards for multiple city agencies and strategies to mitigate the hazard(s). This can include going through the codes enforcement process to resolve the hazard.

\section{Training and Experience}

There are three levels of training for fire fighters in the state of Ohio. These certification levels are:

- Volunteer Fire Fighter: Volunteer fire fighter certification requires 36 hours of training and introduces the student to basic concepts, equipment and techniques. This course does not include fighting real fires. The student may take the state certification examination after successful completion of the course. 


\section{Career Fire Apparatus Operator Died After Falling Down an Unsecured Elevator Shaft at a 5-Story Residential Apartment Building - Ohio}

- Fire Fighter Level I: Level I certification requires a minimum of 120 hours of training. The course provides comprehensive introduction and practice of basic fire fighting concepts and skills, and permits the students to practice these skills, including live fire training.

- Fire Fighter Level II - Level II certification is required for full-time, paid (career) firefighters, and consists of a minimum 240 hours of training. Additional practice of skills is included, and advanced rescue and prevention concepts are introduced, including live fire training.

Both Fire Fighter I and Fire Fighter II training and certification are voluntary for fire fighters in the volunteer fire service and mandatory for career fire fighters.

This fire department operates its own recruit training academy. Recruits work 40 hours per week for a total of 26 weeks, receiving Fire Fighter I and Fire Fighter II training. Recruits then work an additional 6 weeks, receiving emergency medical technician (EMT) training. Recruits who successfully complete the academy training are assigned to fire companies for a 52-week probationary period. Each recruit rotates between engine and truck company assignments. Each recruit receives a probationary training book with defined skill sets that must be accomplished and signed off by both the company officer and the district chief indicating completion. The fire department currently requires 56 hours of annual continuing education units (CEUs) to maintain certification.

Probationary fire fighters wear a blue placard on their helmets to identify their probationary status during the 52-week probationary period. After completing the 52-week probationary period, successfully completing the certification test and finishing their training book, probationary fire fighters are promoted to fire fighter 1 .

Company level training is accomplished in a number of ways including:

After 5 years at the fire fighter 1 rank, a member can test for the fire apparatus operator (FOA) position. After 5 years, a member can also apply to take the "officer-in-charge" test which allows a fire fighter to step up to the higher officer-in-charge rank as needed.

New officers and FAOs work as traveling officers and FAOs, meaning that they could work at any fire company within the city on any shift. The department has two levels of company officer, lieutenants and captain. Lieutenants can test for promotion to the captain rank after 1 year. Captains can test to be district chiefs after 1 additional year. Assistant chiefs and the fire chief position are appointed by the city manager.

The fire department is currently working to revise the promotional process by offering officer training programs. In the past, promotions were solely based on a written civil service examination. The new promotion process will include both written and oral testing components through the state of Ohio and the International Fire Service Accreditation Congress (IFSAC). 


\section{Career Fire Apparatus Operator Died After Falling Down an Unsecured Elevator Shaft at a 5-Story Residential Apartment Building - Ohio}

\section{Equipment and Personnel}

This incident initially involved a dispatch for a report of smoke in a building. One engine (Engine 49), one truck (Truck 31) and District Chief 4 were dispatched for an automatic smoke alarm on fireground channel Delta 8 per fire department procedures. Note: A senior captain (captain on Ladder 31) who was in training for promotion to district chief rode with District Chief 4 on this alarm.

\section{Fire Alarm}

Engine 49:

E49: acting officer-in-charge (OIC), fire apparatus operator (FAO), 2 fire fighters

Ladder 31: L31: lieutenant, fire apparatus operator, 2 fire fighters

District Chief 04

DC4: district chief from District 4 (designated Incident Command), captain from Ladder 31)

The dispatch was upgraded to a box alarm after dispatch received multiple phone calls reporting smoke in the building, building on fire, and occupants trapped by the fire threatening to jump from balconies at the same address. The following equipment and personnel were dispatched on the first alarm assignment per established fire department procedures:

1st Alarm

Engine 31:

Engine 46:

Ladder 18:

Ladder 23:

Heavy Rescue 9

District 01

Medic 46:

ALS 32

Safety Officer
E31: acting officer-in-charge (OIC), fire apparatus operator (FAO), 2 fire fighters

E46: lieutenant, fire apparatus operator (FAO), 2 fire fighters

(Designated as the safety engine and accountability per SOP)

L18: lieutenant, fire apparatus operator (FAO), 2 fire fighters

L23: lieutenant, fire apparatus operator (FAO), 2 fire fighters

(Designated as the rapid assistance team or RAT per SOP)

HR9: lieutenant, fire apparatus operator (FAO), 3 fire fighters

DC1: district chief from District 1)

M46: ambulance unit with 2 paramedics

Advanced Life Support 32: with 1 paramedic lieutenant

SO2: captain assigned as acting shift safety officer

As District Chief 4 was setting up command, the Ladder 31 captain went to do a 360 degree size-up, walking from DC4's vehicle past Side B to Side C. Ladder 31's captain observed fire inside the fire apartment and reported this observation to DC4, who immediately radioed dispatch for an additional engine and ladder company.

\section{Extra Companies at request of Incident Command}

Engine 18

Ladder 32
E18: lieutenant, fire apparatus operator (FAO), 2 fire fighters

L32: lieutenant, fire apparatus operator (FAO), 2 fire fighters 
Career Fire Apparatus Operator Died After Falling Down an Unsecured Elevator Shaft at a 5-Story Residential Apartment Building - Ohio

Incident Command (District Chief 4) requested a second alarm as the incident progressed, resulting in the following companies being dispatched:

$\underline{2^{\text {nd }} \text { Alarm }}$

Engine 8

Heavy Rescue 14

District Chief 3
E8: lieutenant, fire apparatus operator (FAO), 2 fire fighters

HR14: acting officer-in-charge (OIC), fire apparatus operator (FAO) (victim), 2 fire fighters

DC3: district chief from District 3 (assigned to search and rescue operations)

\section{Structure}

The structure involved in this incident was a five-story brick and concrete multi-family apartment building built in 1962. The 31,000 square-foot structure contained 38 separate apartments. The ground floor (Floor 1) contained offices, a mechanical room, storage space and six individual apartments. Floors 2 through 5 contained 8 apartments (both one and two bedroom) and a laundry room. Floors 2 through 5 had identical floor plans. A centrally-located hydraulic elevator provided access to floors 1 through 5. Two stairwells were located near the B/C and C/D corners. Both stairwells provided access to each floor and also ground-level exterior access (see Photo 1, Photo 2 and Diagram 1).

Due to the sloping hillside behind the building, the two apartments on Floor 2 on Side $\mathrm{C}$ had patios that were extended outward at ground level into the hillside (see Photo 2). The Side C rooms on Floor 1 were actually below grade. 


\section{Career Fire Apparatus Operator Died After Falling Down an Unsecured} Elevator Shaft at a 5-Story Residential Apartment Building - Ohio

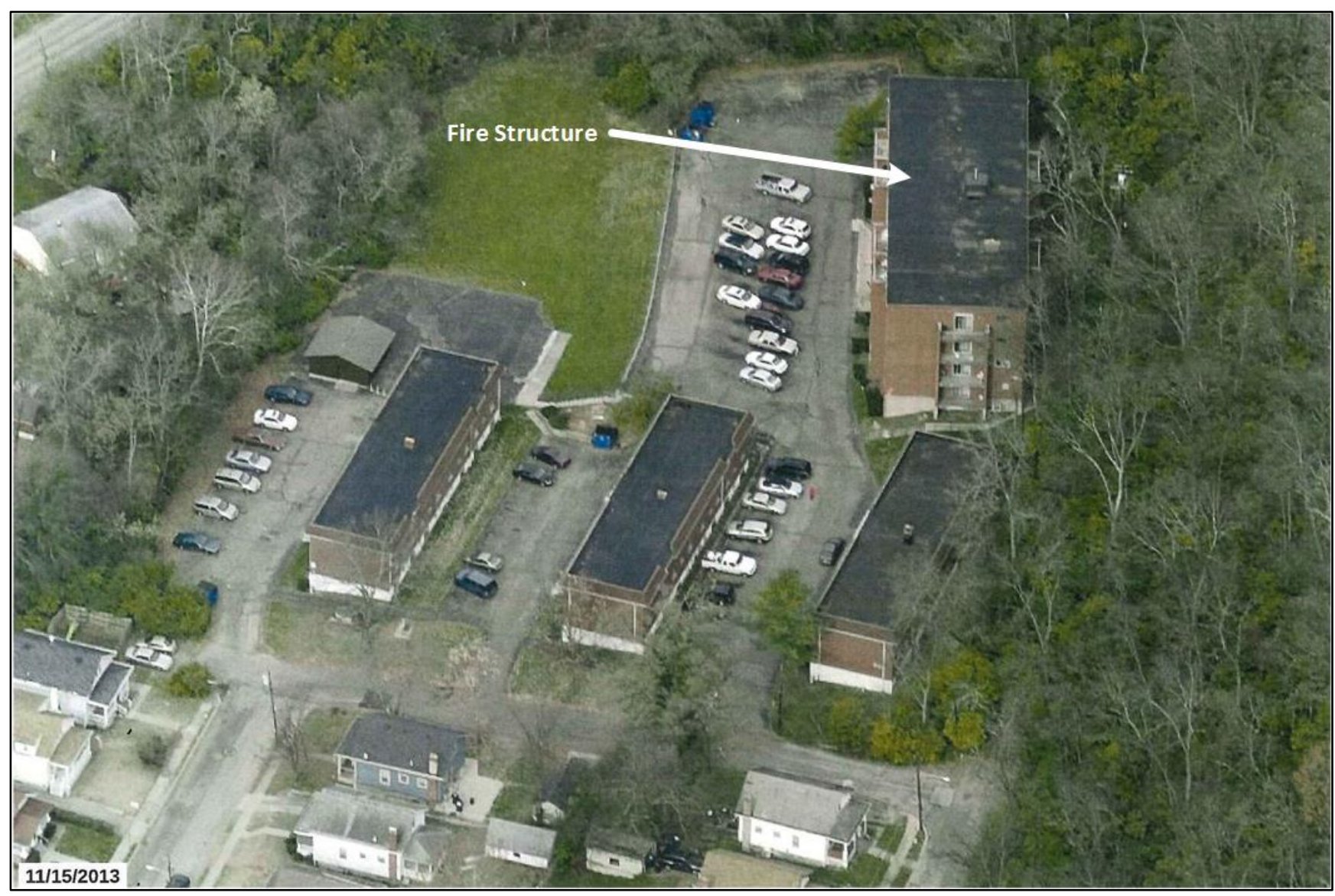

Photo 1. Overhead photo of incident scene.

(Photo courtesy of fire department.) 
Career Fire Apparatus Operator Died After Falling Down an Unsecured Elevator Shaft at a 5-Story Residential Apartment Building - Ohio

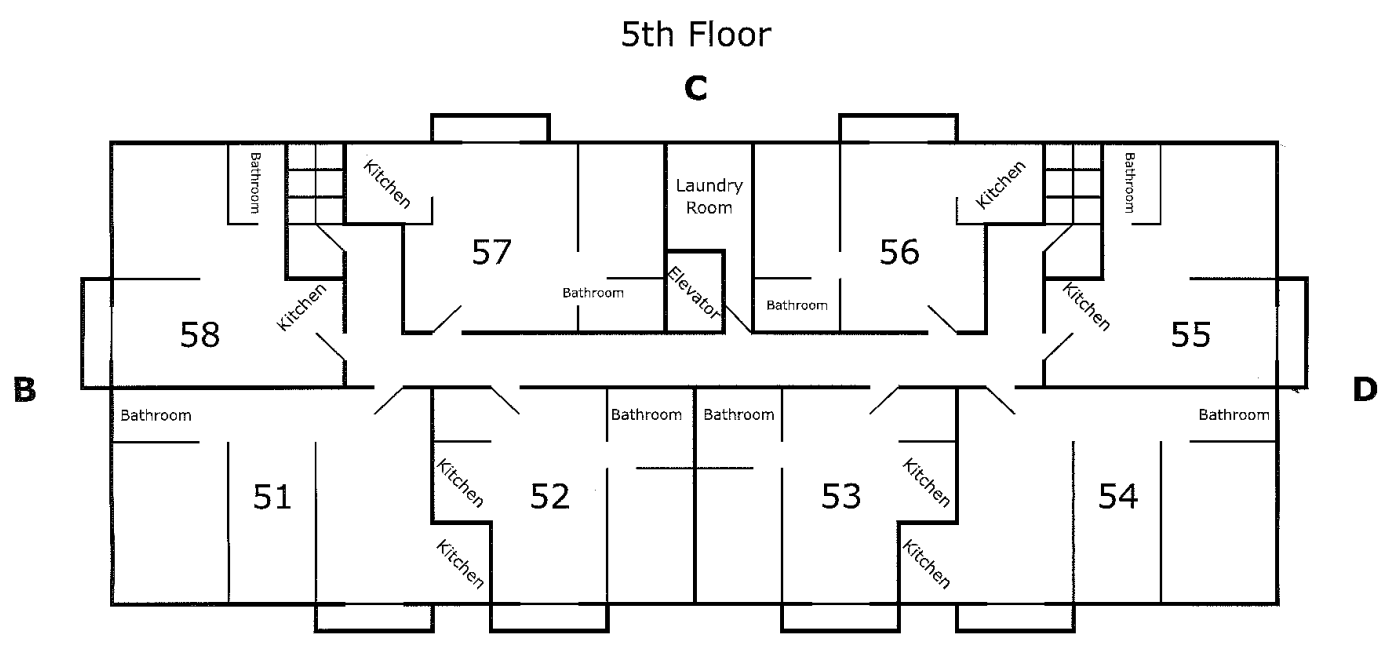

A

Diagram 1. Layout of Floor 5. Floors $2-4$ had similar floorplans.

(Diagram courtesy of fire department.) 


\section{Career Fire Apparatus Operator Died After Falling Down an Unsecured Elevator Shaft at a 5-Story Residential Apartment Building - Ohio}

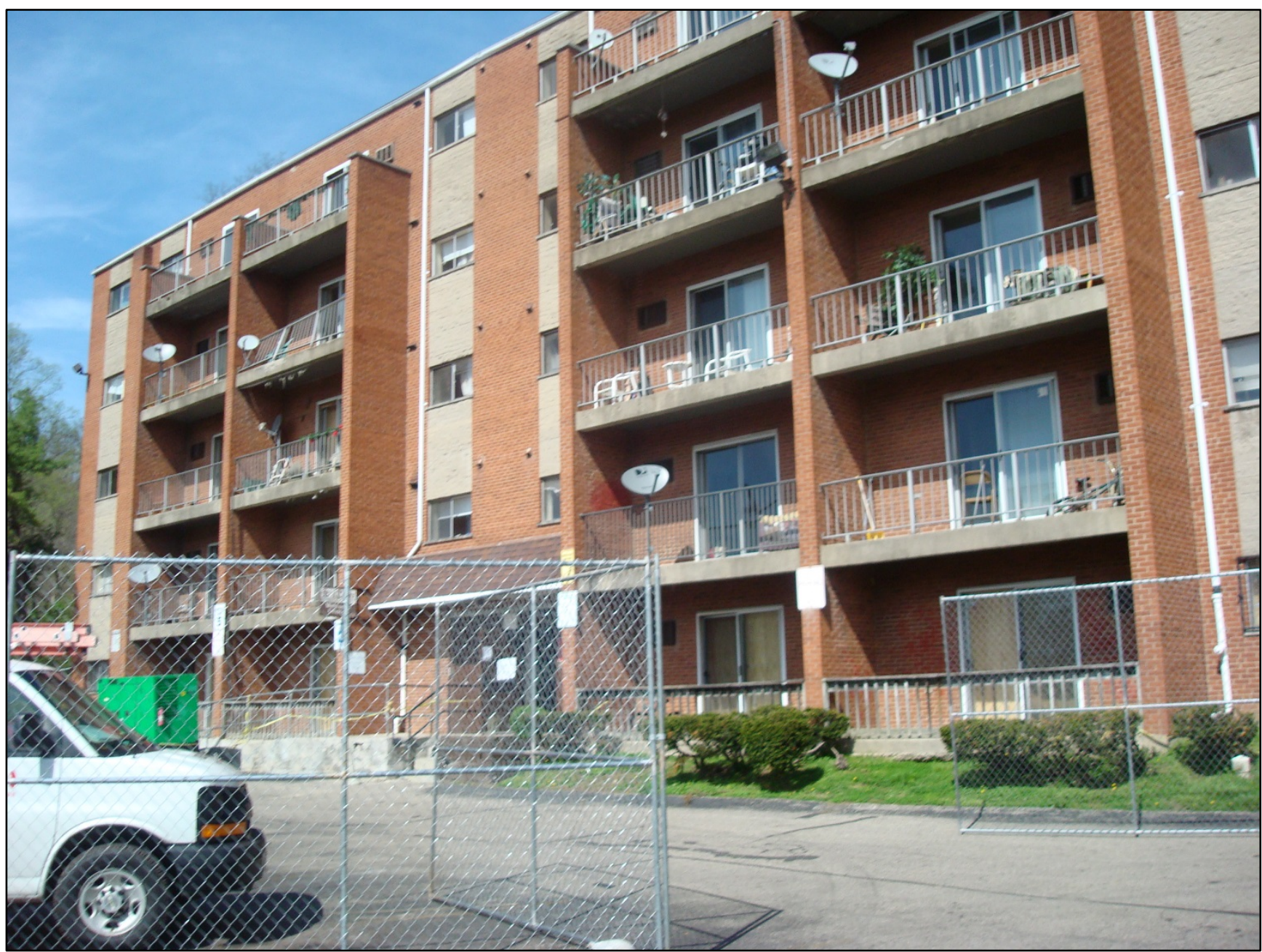

Photo 2. View of apartment Building D, Side A. (Photo NIOSH.)

The structure was part of an apartment complex that was located at the end of a narrow city street and at the top of a steep grade. The fire structure was identified as Building D within the complex and was the largest of the four buildings within the complex. The fire building was located at the very end of the street (see Photo 1). The location was a challenge for arriving fire apparatus due to the narrow streets and limited parking. Later arriving units had to stage several blocks away. Fire fighters and emergency medical services (EMS) personnel had to carry equipment and tools up the grade to the fire structure. The fire department had responded to this apartment complex several times for medical and fire alarm calls.

\section{Elevator}

The five-story apartment building contained a hydraulic elevator that was installed in 1996 . The elevator was centrally located and the elevator shaft measured approximately 76.5 inches by 67 inches. The interior of the elevator car measured approximately 52.5 inches by 48 inches. The elevator car 


\section{Career Fire Apparatus Operator Died After Falling Down an Unsecured Elevator Shaft at a 5-Story Residential Apartment Building - Ohio}

was accessed from each floor by a metal hoistway door which was hinged on the right side and swung outward into the hallway. An elevator call button panel was located on each floor to the left of the elevator door. The elevator system was designed with both mechanical and electrical interlocks designed to keep the hoistway door locked at all times, until the elevator car was properly positioned at the floor of choice. The elevator hoistway doors on Floors 2, 3 and 5 were the original elevator hoistway doors and included the same types of locking mechanisms. The elevator hoistway doors on Floors 1 and 4 had been replaced and contained a different locking mechanism.

After this incident, a local newspaper conducted a survey that determined that twelve other structures within the city contained the same type of elevator with outward swinging doors.

Following the incident, the building ownership contracted to have the elevator inspected on June 8, 2015. Representatives of the building ownership coordinated the elevator inspection and hired an independent consultant to inspect the elevator. The elevator inspection was witnessed by members of the fire department, the International Association of Fire Fighters local union, representatives from the city’s Planning and Buildings Division, a representative of building ownership and NIOSH. This inspection determined that the safety interlocks on the fifth floor were not operating properly, allowing the elevator hoistway door to be opened when the elevator car was not in position at the fifth floor. This allowed access directly to the elevator shaft when the elevator car was not in position on the fifth floor.

\section{Timeline}

Note: This timeline is provided to set out, to the extent possible, the sequence of events as the fire department responded. The times are approximate and were obtained from review of the dispatch audio records, witness interviews, photographs of the scene, SCBA data logger data and other available information. In some cases the times may be rounded to the nearest minute, and not all events have been included. The timeline is not intended, nor should it be used, as a formal record of events.

- 0532 Hours

Dispatch receives notification of second-floor fire alarm in residential apartment building. Engine 49, Ladder 31 and District Chief 4 are dispatched

- 0534 Hours

Dispatch receives multiple phone calls for smoke in building, building on fire, and occupants trying to escape from balconies.

Alarm is upgraded to $1^{\text {st }}$ Alarm assignment

Engine 31, Engine 46, Ladder 18, Ladder 23, Heavy Rescue 9, District Chief 1, District Chief

3, Medic 46, Safety Officer and Advanced Life Support 32 are dispatched.

- 0537.50 Hours

Engine 49 on scene and reports nothing showing in six-story brick multi-family dwelling. 
Career Fire Apparatus Operator Died After Falling Down an Unsecured Elevator Shaft at a 5-Story Residential Apartment Building - Ohio

- 0541.44 Hours

District Chief 4 (Command) on scene and reports working fire and requests additional engine and ladder companies. Engine 18 and Ladder 32 dispatched.

Ladder 31 on scene.

- 0545 Hours

Heavy Rescue 9 on scene.

- 0547 Hours

Engine 31 on scene.

Command (District Chief 4 ) requests $2^{\text {nd }}$ Alarm assignment.

Engine 8, Heavy Rescue 14, and District Chief 3 dispatched.

- 0549 Hours

Ladder 23 (Rapid Assistance Team) on scene.

- 0550 Hours

Engine 46 and Ladder 18 on scene.

- 0551.35 Hours

District Chief 4 (IC) requests Engine 49 FAO to start water to Engine 49 hoseline.

- 0551.48 Hours

Heavy Rescue 9 lieutenant radios that fire is extending into $2^{\text {nd }}$ floor hallway.

- 0552.59 Hours

Command directs Engine 46 to lay a line to the second floor. Note: Engine 46 was the designated safety and accountability engine.

- 0553 Hours

Shift Safety Officer on scene.

- 0554.25 Hours

Heavy Rescue 9 lieutenant radios Command and requests that the Engine 49 hoseline be extended by two sections.

- 0555 Hours (approximate)

Ladder 32 on scene.

District Chief 1 pulls dry hoseline from C/D corner around Side C to the fire apartment and attempts to radio for water but is not on fireground channel B2 (The channel had been changed from the initial Delta 8 to Bravo 2 per procedures due to the working fire). District Chief 1 directs Engine 46 FAO to go back to Engine 31 to pressurize hose line. 
Career Fire Apparatus Operator Died After Falling Down an Unsecured Elevator Shaft at a 5-Story Residential Apartment Building - Ohio

- 0555.54 Hours

Engine 31 FAO starts water to exterior hose to Side C.

- 0558 Hours (approximate)

Engine 49 crew forced to evacuate due to extreme fire conditions in the second floor hallway.

- $\quad 0600.18$ Hours

Heavy Rescue 9 lieutenant radios that water is on the fire.

- 0601.03 Hours

Safety Officer radios that Engine 49 Acting officer-in-charge has been burned.

- 0602.14 Hours

Command radios that fire has been knocked down but still has heavy smoke on all floors.

- 0604 Hours (approximate)

Heavy Rescue 14 on-scene. Command directs crew to search fifth floor.

- 0607.25 Hours

Dispatch receives phone calls reporting female with small child trapped on fifth floor.

- 0609-0610 Hours

Heavy Rescue 14 crew ascends B/C stairway to fifth floor. Last crew member to go on air is Heavy Rescue 14 FAO at 0610 hours.

- 0612 Hours (approximate)

Heavy Rescue 14 FAO falls down elevator shaft.

- $\quad 0615.36$ Hours

Heavy Rescue 14 acting officer-in-charge radios that fifth floor is clear.

- 0619.43 Hours

Command requests personnel accountability report (PAR) from all crews.

Heavy Rescue 14 acting officer-in-charge realizes Heavy Rescue 14 FAO is missing and crew begins searching fifth floor apartments for missing FAO.

- 0622.23 Hours

Heavy Rescue 14 acting officer-in-charge radios Mayday for Heavy Rescue 14 FAO down elevator shaft.

- 0636.23 Hours

Special Operations chief radios that Heavy Rescue 14 FAO has been extricated and is being carried outside. 


\section{Career Fire Apparatus Operator Died After Falling Down an Unsecured Elevator Shaft at a 5-Story Residential Apartment Building - Ohio}

- 0647 Hours

Medic 19 enroute to hospital transporting Heavy Rescue 14 FAO.

\section{Personal Protective Equipment}

The Heavy Rescue 14 FAO was wearing his full array of department-issued turnout gear including station uniform, work boots, hood, helmet, turnout pants and turnout coat at the time of the incident. The FAO was also wearing a self-contained breathing apparatus with an integrated PASS device and a flashlight. NIOSH investigators inspected the protective clothing and turnout gear worn at the time of the incident. Custody of the self-contained breathing apparatus was transferred to NIOSH for further evaluation and testing. See Appendix One for a summary of the NIOSH evaluation and test report. The SCBA showed damage that was attributed to the fall, including broken connection points on the SCBA backframe, shoulder strap attachment and cylinder attachment points. Due to their condition, a new facepiece and cylinder were obtained for use during the NIOSH testing. The SCBA and turnout gear were not considered to have contributed to this fatality.

The fire department uses a fireground electronic accountability system (EAS) produced by the manufacturer of their self-contained breathing apparatus. The EAS is built into the personal alert safety system (PASS) and transmits to a computerized electronic control panel and display located in the district chief's vehicle. This system must be activated at the control panel at the start of an emergency operation.

\section{SCBA Internal Data}

The National Fire Protection Association (NFPA) 1981, Standard for Open-Circuit Self-Contained Breathing Apparatus (SCBA) for Emergency Services, 2013 edition, required SCBA certified to that standard to collect and retain air management and life support data. The SCBA involved in this incident was certified to the 2007 edition of NFPA 1981 and this data collection capability was incorporated. This data can be collected and retained for a limited period of time when properly isolated and restricted after an incident. The fire department correctly isolated and restricted access to the SCBA allowing NIOSH to obtain this data with the assistance of the manufacturer. On May 22, 2015, the SCBA was transported to the manufacturer's facility in Pennsylvania where the data logger data was successfully downloaded by the manufacturer. Representatives of the fire department, the IAFF local and NIOSH witnessed the downloading process.

This data was used to identify the time when the Heavy Rescue 14 FAO went on air and when the cylinder ran out of air. This information was used in constructing the overall timeline for this incident.

\section{Weather Conditions}

At the time of the incident, the weather in the immediate area was overcast with light rain and variable winds of approximately 4.6 miles per hour (mph). The temperature was approximately 47 degrees 


\section{Career Fire Apparatus Operator Died After Falling Down an Unsecured Elevator Shaft at a 5-Story Residential Apartment Building - Ohio}

Fahrenheit [Weather Underground 2015]. The weather was not considered to be a factor in this incident.

\section{Investigation}

On March 26, 2015, a 54-year-old male career fire apparatus operator (FAO) suffered a fatal fall down an unsecured elevator shaft while searching the fifth floor of a five-story residential apartment building during a working fire incident.

At approximately 0532 hours, Engine 49, Ladder 31 and District Chief 4 were dispatched for an automatic fire alarm on radio channel fire group Delta 8 (D8), per departmental procedures. The fire department had been frequently dispatched to this address for automatic fire alarm calls and emergency medical services (EMS) calls. At 0534 hours, the city emergency communications center (ECC) received multiple calls from the address reporting smoke in the building, the building on fire, and residents trying to escape from elevated balconies. The alarm was upgraded to a working fire alarm that included Engine 49, Engine 31, Engine 46, Ladder 31, Ladder 18, Ladder 23, District Chief 1, Heavy Rescue 9, Medic 46, the shift safety officer (Safety Officer 2) and a medical supervising lieutenant (Advanced Life Support (ALS) 32). The radio talk group channel was changed from fire alarm Delta 8 to fire group Bravo 2 per standard operating procedures. Also, per standard operating procedures, the third due truck, Ladder 23, was designated as the Rapid Assistance Team (RAT) and the third due engine, Engine 46, was designated as the Safety and Accountability Engine.

\section{Engine 49}

Engine 49 was staffed by an acting officer (officer-in-charge or OIC), two fire fighters and a fire apparatus operator (FAO). E49 arrived on scene at approximately 0538 hours, caught the closest hydrant and laid out a 5-inch supply line as it drove up the narrow street into the parking lot in front of the fire building, Building D (see Photo 1 and Diagram 2). Engine 49 was positioned to the south of the fire building to allow room for Ladder 31 to position in front of (west side of) the apartment building. The Engine 49 OIC radioed a size-up reporting no fire showing. The Engine 49 fire fighter 1 got off the truck and was immediately approached by an occupant who told him that the fire had started in her apartment on the second floor from cooking materials left unattended on her stove. The Engine 49 fire fighter 1 followed the occupant through the front entrance to check on the size of the fire, thinking that it could be easily extinguished with a pot of water. They walked up the steps near the B/C corner to the second floor. The Engine 49 fire fighter 1 reported having to don his SCBA facepiece and go on air due to the smoke conditions in the second floor hallway. The Engine 49 fire fighter 1 advanced to the apartment door (Apartment 27) and observed that the door knob felt very hot to the touch. He opened the door, quickly looked inside and observed heavy smoke. The Engine 49 fire fighter 1 then closed the apartment door and with the civilian occupant of Apartment 27 returned to the outside to meet the rest of the Engine 49 crew.

\section{District Chief 4}

District Chief 4 arrived on scene at 0541 hours and surveyed the apartment building as he drove past the front of the building and parked his vehicle facing the A/B corner. A senior fire captain assigned to Ladder 31 was riding with District Chief 4 and was training to step up and serve as an acting district 


\section{Career Fire Apparatus Operator Died After Falling Down an Unsecured Elevator Shaft at a 5-Story Residential Apartment Building - Ohio}

chief. The Ladder 31 captain left the district chief's vehicle and proceeded to do a 360-degree size up walking around Side B to Side C. District Chief 4 radioed the ECC confirming the working fire and assumed incident command. District Chief 1 arrived on scene and reported to the command post on Side A. District Chief 1 was directed by Command to do a 360 degree size up. District Chief 1 switched his radio to what he thought was the fireground channel but set his radio on the wrong channel.

The incident commander (District Chief 4) assigned Engine 49 to pull a 1 3/4-inch preconnected crosslay to the second floor. The Engine 49 OIC pulled the crosslay off Engine 49 and pulled it around Side D to Side C (see Photo 3 and Photo 4) to reach the exterior stairwell exit door located on Side C near the C/D corner (see Photo 5 and Diagram 2). The Engine 49 FAO helped flake out the hose while the Engine 49 fire fighter 2 walked from the hydrant approximately 2 blocks away to catch up with the crew. The Engine 49 OIC pulled the uncharged hoseline up the C/D stairway and started to advance down the hallway. The Engine 49 OIC observed dense dark smoke and felt heat as he advanced but couldn't see any fire. He advanced the hose as far as he could but was short of the fire apartment because the hoseline had snagged on the stair treads between the ground level and second-floor landing (see Photo 6). He heard the Heavy Rescue 9 crew coming down the hallway from Side B toward him. The incident commander directed Engine 31 to take in a second hose line. At approximately 0551 hours, the Engine 49 OIC radioed for the hoseline to be charged as the Engine 49 fire fighter 2 was following the hoseline into the second floor hallway to meet him. When the hoseline was charged, the pressure in the hoseline knocked the Engine 49 fire fighter 2 off balance and dislodged her facepiece. As the Engine 49 OIC moved to assist the Engine 49 fire fighter 2, the conditions in the hallway rapidly deteriorated as the fire and heat intensified. The Engine 49 OIC felt his hands burning through his gloves and told the Engine 49 fire fighter 2 that they had to get out of the building. They followed the hoseline outside and returned to Engine 49 where medics treated the Engine 49 OIC for burns and prepared to transport him to a local hospital.

The Ladder 31 captain walked to Side $\mathrm{C}$ and observed fire and heavy smoke inside the fire apartment and immediately walked back to the command post to report this observation to command. The sliding glass patio doors of the fire apartment were still intact at this time. Soon after, command (District Chief 4) radioed a working fire transmission to the ECC at 0542 hours. The incident commander requested an additional engine and ladder for resources. Engine 18 and Ladder 32 were dispatched. 


\section{Career Fire Apparatus Operator Died After Falling Down an Unsecured} Elevator Shaft at a 5-Story Residential Apartment Building - Ohio
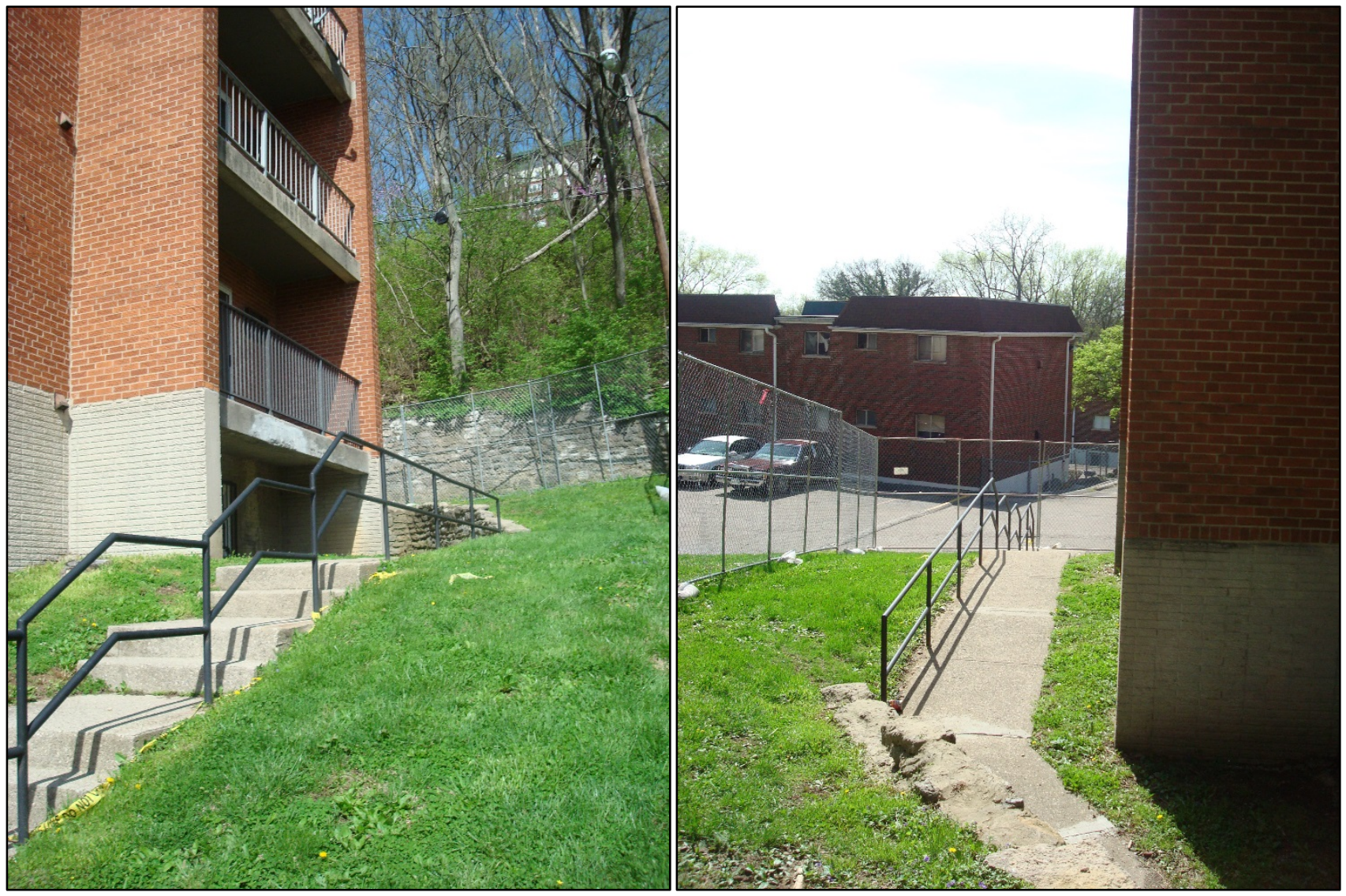

Photo 3 and Photo 4. Photos show the route the Engine 49 crew used to advance the initial attack hoseline along Side $\mathbf{D}$ to Side $\mathrm{C}$ to access the stairwell door on Side $\mathrm{C}$.

(NIOSH Photos). 


\section{Career Fire Apparatus Operator Died After Falling Down an Unsecured} Elevator Shaft at a 5-Story Residential Apartment Building - Ohio

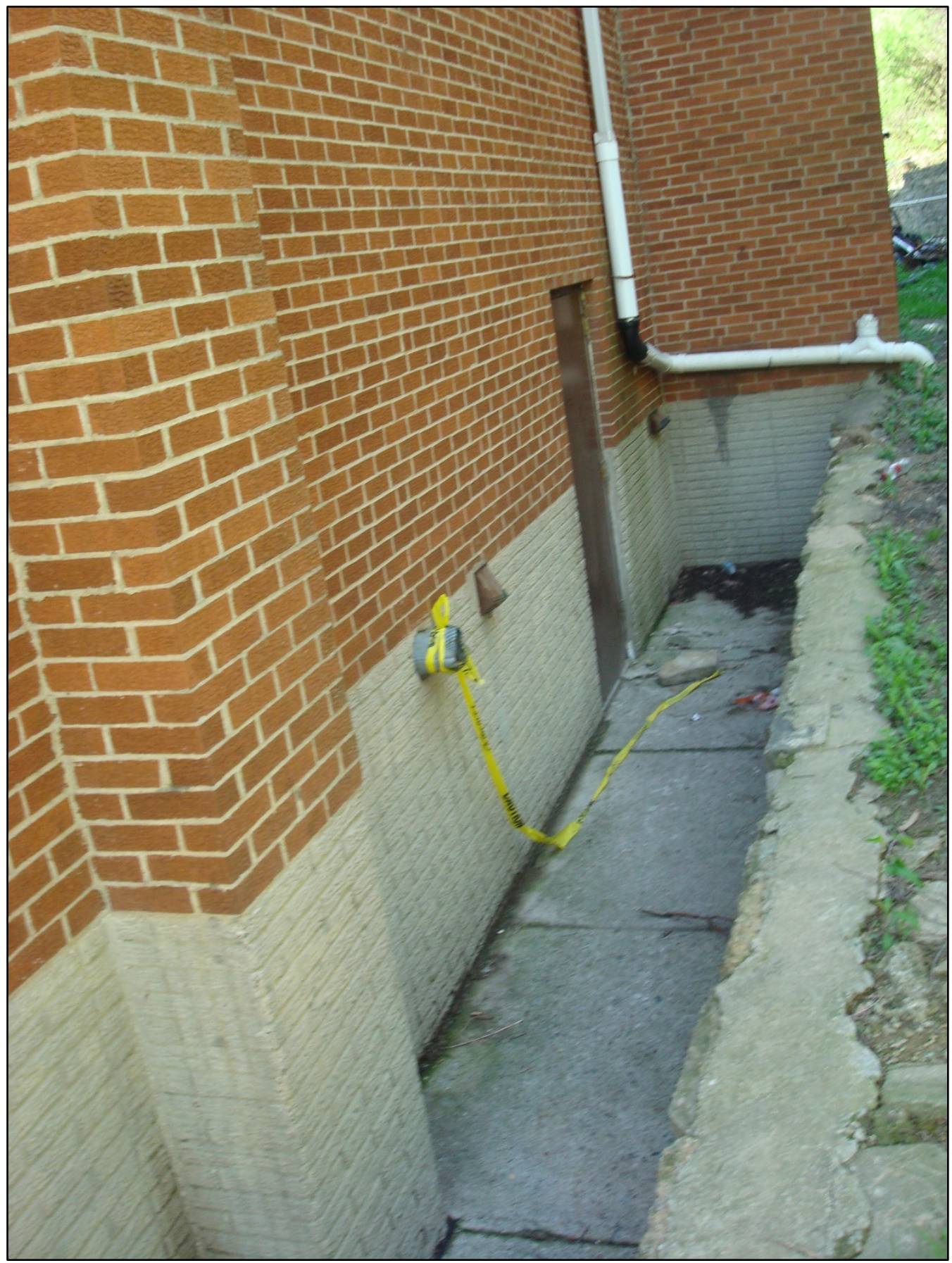

Photo 5. Stairwell door on Side $C$ near the C/D corner where the Engine 49 crew entered structure with initial attack hoseline. This door opens to the stairway landing between the first and second floors.

(NIOSH Photo.) 


\section{Career Fire Apparatus Operator Died After Falling Down an Unsecured Elevator Shaft at a 5-Story Residential Apartment Building - Ohio}

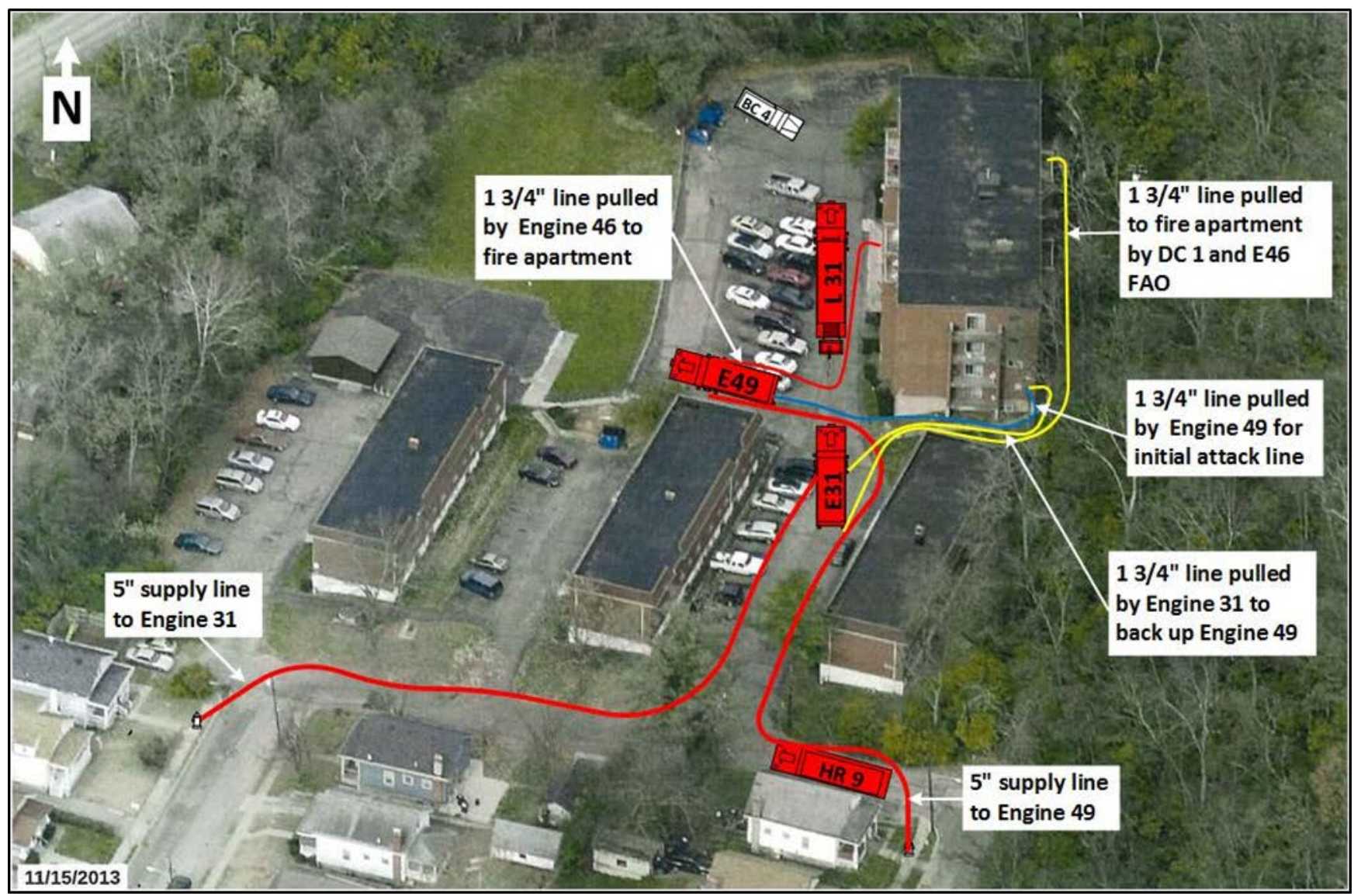

Diagram 2. Apparatus placement and hoseline deployment of the initial responding companies. Locations are approximate and not all responding companies are shown.

(Adapted from photograph provided by fire department.)

\section{Ladder 31}

Ladder 31 arrived on scene at 0541 hours and was directed by the incident commander (District Chief 4) to stage near the front entrance. Ladder 31 set up near the front entrance and started to raise the aerial platform up to the roof. Two civilians appeared on a second floor balcony. The Ladder 31 FAO and fire fighter 2 quickly put up a ground ladder to the second floor balcony and assisted the two civilians to the ground.

The Ladder 31 lieutenant and fire fighter 1 proceeded to the front door and briefly spoke with civilians coming out of the building about the location of the fire. They proceeded toward the B/C corner to find the stairway. They met the Engine 49 fire fighter 1 in the stairway as he was returning from sizing up the fire apartment and asked if a hoseline was in position yet. The Ladder 31 captain who was riding with District Chief 4 came in the exterior door from Side $\mathrm{C}$ and told the Ladder 31 lieutenant and fire fighter 1 that he needed them to vent the glass patio door to the fire apartment. The Ladder 31 lieutenant and fire fighter 1 walked outside and proceeded to the patio of Apartment 27. The fire 
Career Fire Apparatus Operator Died After Falling Down an Unsecured Elevator Shaft at a 5-Story Residential Apartment Building - Ohio

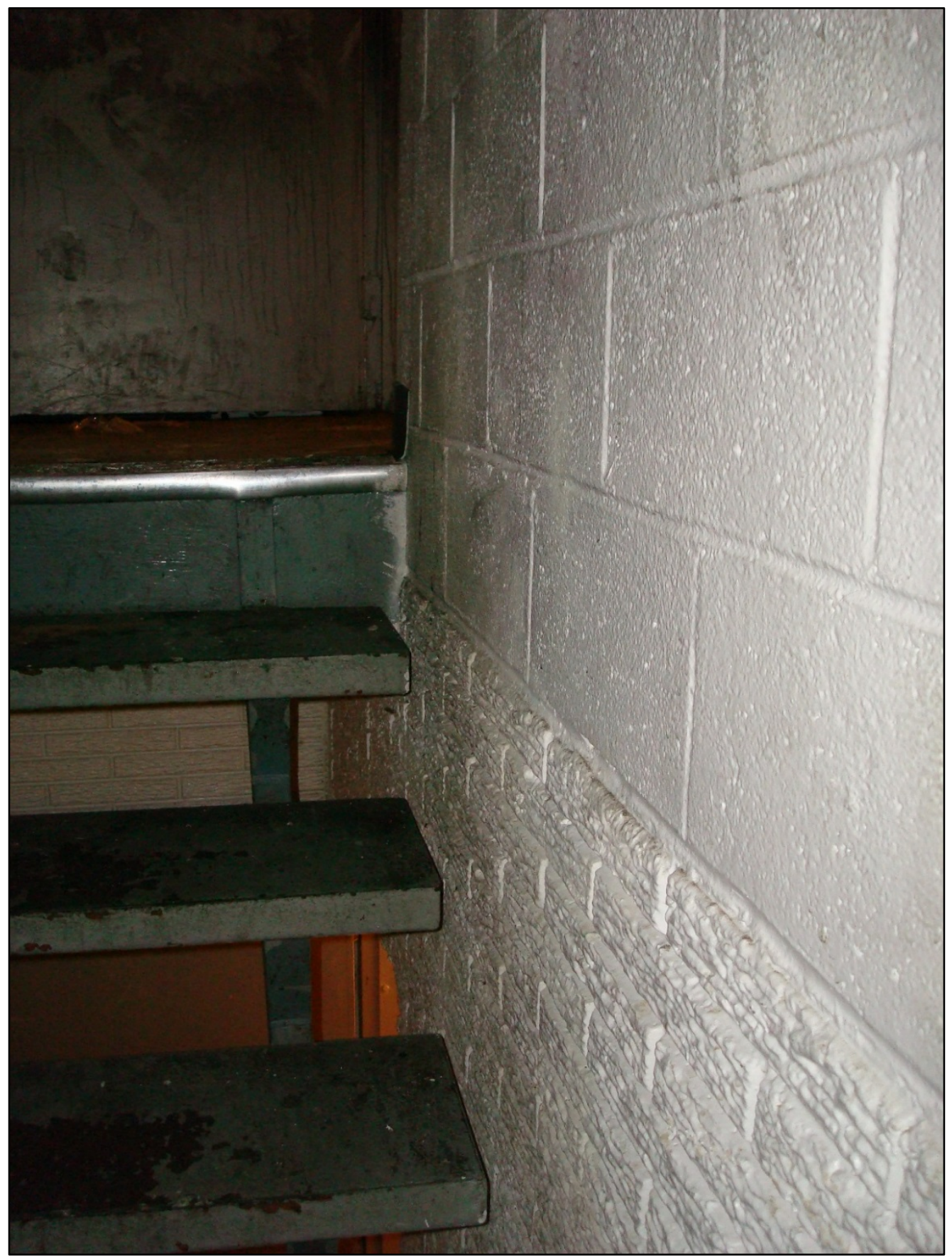

Photo 6. View of stairway between ground level and second floors where the Engine 49 hoseline snagged on stair treads. When the hoseline was charged, the hose became stuck preventing the hose from being advanced into the fire apartment. Note clearance between stair tread and wall where the hose became stuck.

(NIOSH Photo.) 


\section{Career Fire Apparatus Operator Died After Falling Down an Unsecured Elevator Shaft at a 5-Story Residential Apartment Building - Ohio}

fighter used an axe to break out the sliding glass patio door. The Ladder 31 lieutenant and fire fighter 1 then returned to the second floor via the BC stairway (see Photo 7).

After the Ladder 31 FAO and fire fighter 2 completed the civilian rescue, the command instructed them to take a $2 \frac{1}{1} 2$-inch hose line to Side C. Soon after that, the incident commander changed the order and instructed the Ladder 31 FAO and fire fighter 2 to go to Side C and report to District Chief 1. The Ladder 31 FAO and fire fighter 2 proceeded to Side C where they observed District Chief 1 operating a $13 / 4$-inch preconnected hoseline from Engine 31. They took the hoseline from District Chief 1 and worked the hoseline through the patio doors into the fire apartment. Due to the sloping hillside behind the building, the two second floor apartments on Side $\mathrm{C}$ had patios that were extended at ground level into the hillside (see Photo 7). The Side C rooms on the first floor were actually below grade.

\section{Engine 31}

Engine 31 arrived on scene with a crew of four including a senior fire fighter serving as the acting officer-in-charge (OIC). Engine 31 caught a hydrant southwest of the complex and laid out a 5-inch supply line as it proceeded to the fire building as far as they could go without running over the Engine 49 supply line. Engine 31 staged near the south end of the fire building. The incident commander directed Engine 31 to pull a hoseline to back up Engine 49. The Engine 31 OIC and fire fighter 1 pulled a 1 3/4 inch preconnected crosslay to the exterior door on Side C and followed the Engine 49 hoseline up the stairs. Just as they met the Engine $49 \mathrm{crew}$, they heard the Engine 49 OIC yell that his hands were burning and they had to get out. The Engine 31 and Engine 49 crews exited the second floor at the same time and proceeded outside.

\section{Heavy Rescue 9}

Heavy Rescue 9 arrived on scene at 0545 hours with a crew of five (lieutenant, fire apparatus operator and 3 fire fighters). The supply line to Engine 31 was still flat so Heavy Rescue 9 drove over it to get closer to the scene. The Heavy Rescue 9 lieutenant and three fire fighters immediately walked up the street to the fire building. The Heavy Rescue 9 FAO donned his personal protective clothing and gear and walked up to the scene. He carried a pike pole and a thermal imager. The Heavy Rescue 9 FAO heard District Chief 1 verbally calling for ladders on Side C. The Heavy Rescue 9 FAO grabbed a 16foot straight ladder off Engine 31 and took it around Side D to Side C with the assistance of the Engine 31 FAO. They observed multiple civilians on the outside balconies (third through fifth floors) at Side $\mathrm{C}$ calling for assistance to get off the balconies.

At 0547 hours, command requested a second alarm. Engine 8, Heavy Rescue 14, and District Chief 3 were dispatched on fire group channel Delta 2 (D2). The department special operations chief selfdispatched to the scene after hearing the fireground radio traffic. The special operations chief had previously worked in this district and was familiar with the structure. 


\section{Career Fire Apparatus Operator Died After Falling Down an Unsecured Elevator Shaft at a 5-Story Residential Apartment Building - Ohio}

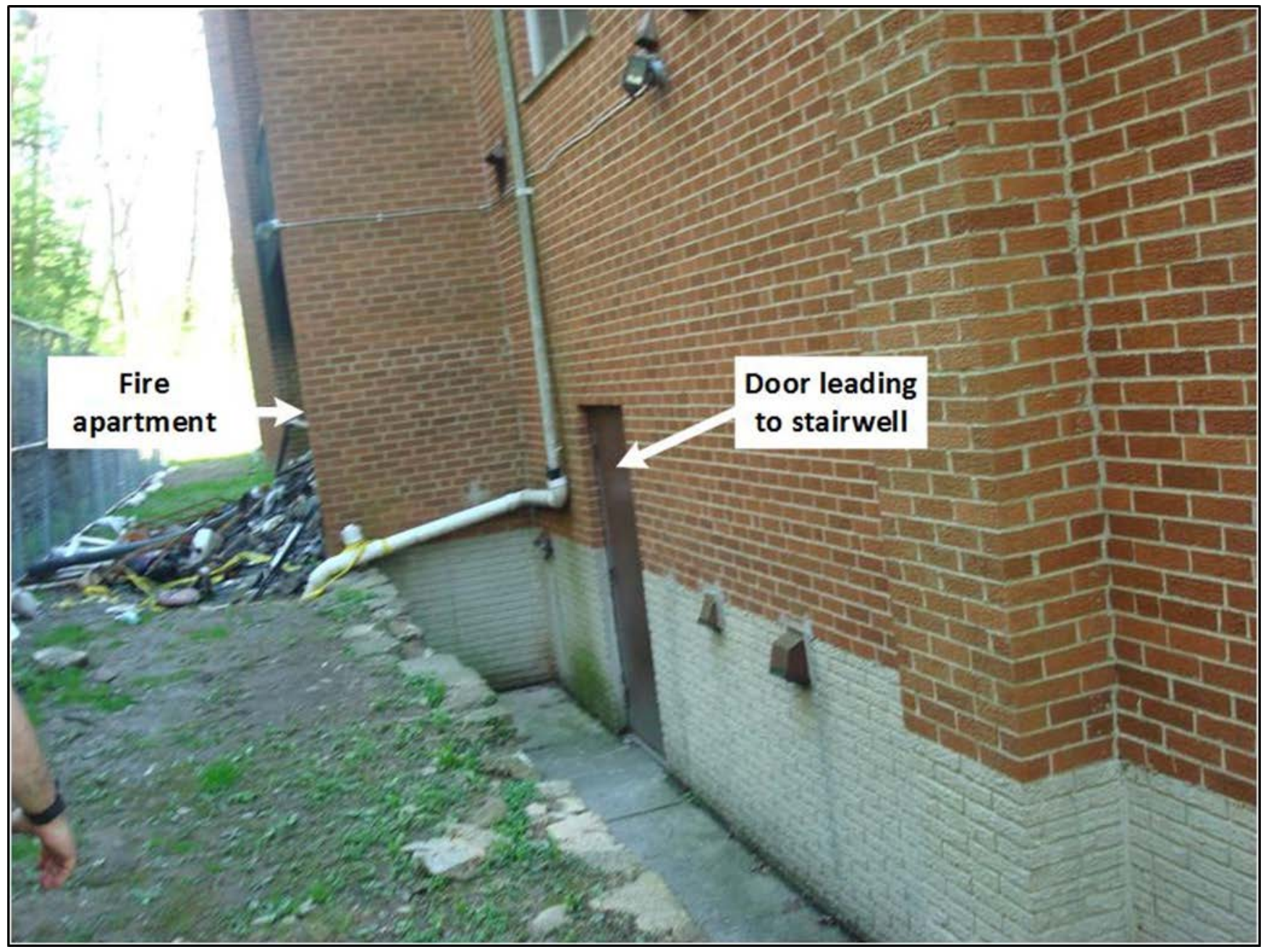

Photo 7. View of apartment building, Side C, looking from Side B toward Side D. The fire apartment is indicated. Note that the two Side $\mathrm{C}$ apartments on the second floor have ground level patios. The exterior door accesses the $\mathrm{B} / \mathrm{C}$ stairwell at the landing between the first and second floors. (Photo NIOSH.)

Access to the apartment building and surrounding buildings were blocked after the supply lines to Engine 49 and Engine 31 were charged. This forced later arriving units and ambulances to stage at least one or more blocks away. Additional crews arriving on scene reported to Command for assignment. Crews were assigned to rescue civilians from the exterior balconies and to conduct interior searches of the apartments on the second through fifth floors.

Diagram 2 shows the apparatus placement and hoseline deployment for the initial responding crews. 


\section{Career Fire Apparatus Operator Died After Falling Down an Unsecured Elevator Shaft at a 5-Story Residential Apartment Building - Ohio}

The Heavy Rescue 9 lieutenant and three fire fighters approached the building to enter through the main lobby area. They observed civilian residents on multiple balconies waiting to be rescued. They observed smoke coming out of open balcony doors. The Heavy Rescue 9 crew was directed to the stairway near the $\mathrm{B} / \mathrm{C}$ corner after they entered the main lobby. They reported that smoke conditions were light as they began climbing the stairs but the smoke increased as they got near the second floor. The Heavy Rescue 9 crew met the Ladder 31 lieutenant and fire fighter 1 at the second floor landing. The Ladder 31 crew were yelling that they needed a hoseline on the second floor. The Ladder 31 lieutenant radioed Command that a hoseline was needed at their position in the B/C stairway. They wedged open the stairway door as they waited for a hoseline.

The Heavy Rescue 9 lieutenant and 3 fire fighters advanced into the second floor hallway where they encountered intense heat and thick smoke. When they came to the fire apartment on their left, the Heavy Rescue 9 lieutenant observed that the door was open and fire was blowing across the hallway. The apartment door across the hallway to their right had caught fire. They also observed the linoleum tile on the floor in front of the fire apartment burning. The Heavy Rescue 9 lieutenant tried to close the door to the fire apartment with a ceiling hook but the fire had already consumed the top portion of the door.

The Heavy Rescue 9 lieutenant and two of the fire fighters advanced past the fire apartment to search the rest of the second floor. One of the Heavy Rescue 9 fire fighters remained with the Ladder 31 crew. They met the Engine 49 OIC in the hallway with the nozzle of the Engine 49 hoseline. The nozzle was just short of the doorway to the laundry room (see Diagram 3). The Heavy Rescue 9 lieutenant radioed to command that the Engine 49 hoseline was short and needed two more sections of hose added in order to reach into the fire apartment. At this point the Heavy Rescue 9 fire fighters did not know that the hoseline was stuck on the stairway treads in the C/D stairway. The incident commander did not want to shut down the Engine 49 hoseline to add extra hose sections due to the fire conditions. He did not know that the hoseline was not yet flowing water.

The two Heavy Rescue 9 fire fighters searched the laundry room behind the elevator using a thermal imager. The conditions worsened while they were searching the laundry room. The Heavy Rescue 9 lieutenant crawled back to the fire apartment door and radioed to command that crews still did not have water on the fire. The incident commander asked the Heavy Rescue 9 lieutenant if he could control the apartment door and the lieutenant replied that the apartment door was already burned through. The Heavy Rescue 9 lieutenant turned around and advanced down the hallway to meet his crew. He encountered two nozzles lying on the floor with no fire fighters around. The Heavy Rescue 9 lieutenant picked up the nearest nozzle and began directing water on the ceiling toward the fire. He heard radio traffic that there was a flashover on the second floor. The Heavy Rescue 9 lieutenant did not know that the Engine 49 OIC had suffered burn injuries to his hands and left the building. The Heavy Rescue 9 lieutenant directed water toward the fire for a short time to cool the hallway and then advanced toward Side D to look for his crew.

The Heavy Rescue 9 lieutenant and two Heavy Rescue 9 fire fighters regrouped in the C/D stairwell and advanced up the C/D stairs to the third floor where they encountered several fire fighters. The 


\section{Career Fire Apparatus Operator Died After Falling Down an Unsecured Elevator Shaft at a 5-Story Residential Apartment Building - Ohio}

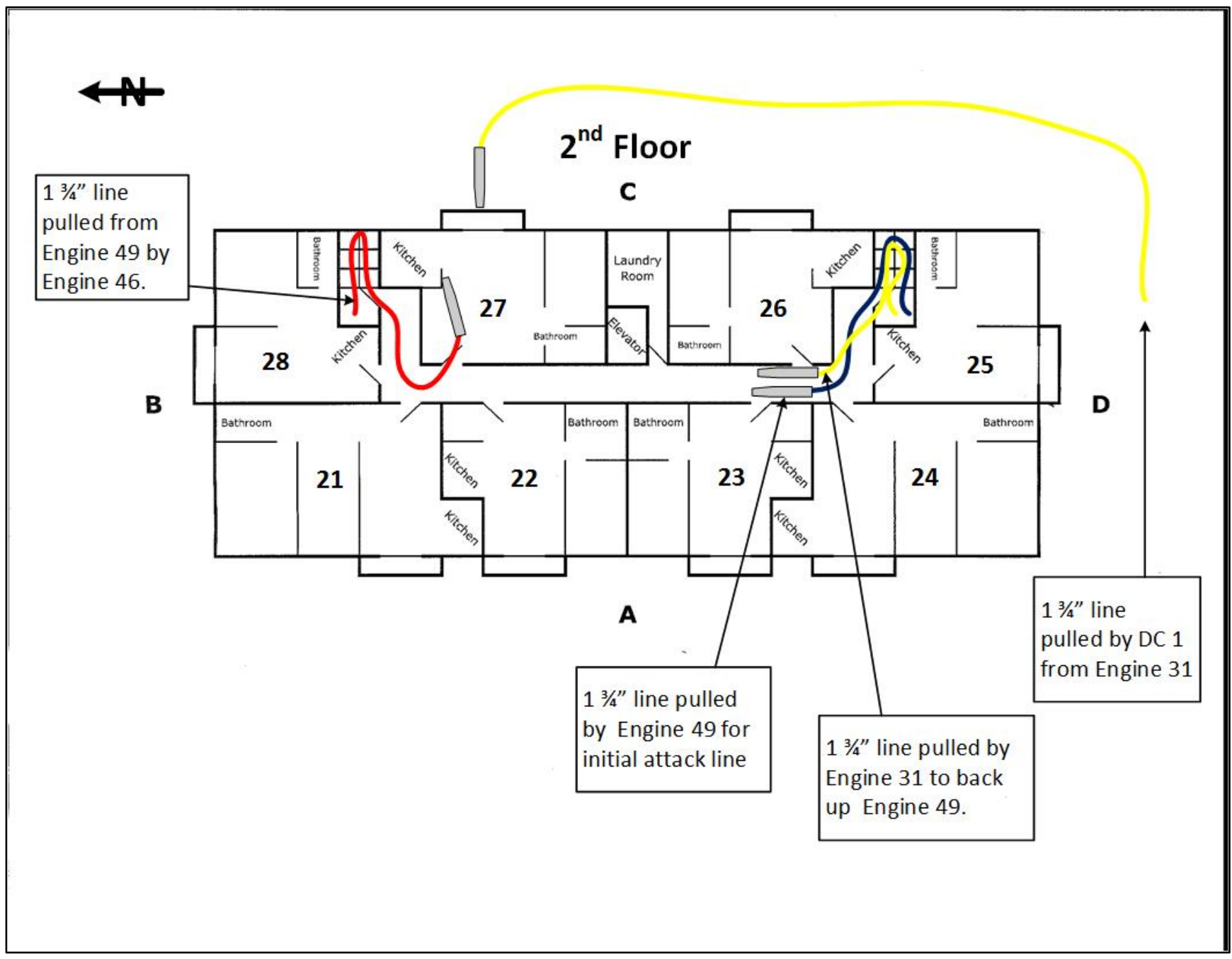

Diagram 3. Location and sizes of hoselines pulled to attack fire in Apartment 27. (Source NIOSH: Adapted from floorplan provided by fire department.)

Heavy Rescue 9 crew advanced up to the fourth floor and began forcing doors to search the fourth floor apartments. They met District Chief 3 who was assigned as the Search and Rescue Operations Chief. District Chief 3 directed the Heavy Rescue 9 crew to force open the elevator hoistway door to make sure there were no civilians trapped in the elevator. District Chief 3 then proceeded to the fifth floor.

The Heavy Rescue 9 crew opened the elevator hoistway door and looked down the shaft but initially didn’t observe anything. At about the same time, they heard the Heavy Rescue 14 OIC radio a 


\section{Career Fire Apparatus Operator Died After Falling Down an Unsecured Elevator Shaft at a 5-Story Residential Apartment Building - Ohio}

Mayday. The Heavy Rescue 9 crew reopened the elevator door and they observed a fire helmet on top of the elevator car. The Heavy Rescue 9 crew immediately rushed down to the first floor, opened the first floor elevator hoistway door, and entered the elevator pit. They observed that a fire fighter was trapped between the elevator shaft wall and the rear of the elevator car. They could not reach the trapped fire fighter. The Heavy Rescue 9 lieutenant sent the two fire fighters to retrieve tools and a ladder.

The Heavy Rescue 9 and Engine 49 fire fighter 1 placed the ladder up to the first balcony on the third floor (Apartment 36). Civilians on the fifth floor (Apartment 56) were yelling for assistance. The Heavy Rescue 9 FAO told the civilians on the fifth floor balcony that they would be right back with a longer ladder. The Heavy Rescue 9 FAO retrieved an extension ladder with the assistance of Engine 49 fire fighter 1 . The 24-foot extension ladder was carried to Side $C$ and raised but it only reached to the fourth floor balcony. A female civilian appeared on the fourth floor balcony (Apartment 46) waiting to be rescued. After helping the female civilian from Apartment 46 down the ladder, The Heavy Rescue 9 FAO and the Engine 49 fire fighter 1 returned to the fourth floor balcony and helped the civilians in Apartment 56 climb down from the fifth floor balcony to the fourth floor balcony and then down the ladder to the ground. Following this rescue, the Heavy Rescue 9 FAO and Engine 49 fire fighter 1 searched Apartments 36 and 46. They briefly stepped out into the third floor hallway and observed smoke but no heat. The Engine 49 fire fighter 1 ran low on air and had to climb down to the ground and retrieve another air cylinder.

\section{Engine 46}

Engine 46 was dispatched on the first alarm as the Safety and Accountability Engine (third due engine) with a crew of four. As the third due engine, E46 was responsible for safety and accountability on the fireground per standard operating procedures. This included setting up the electronic accountability system (EAS) at the command post. Engine 46 arrived on scene at approximately 0550 hours. They were immediately told by Command that they would be going to work. Command directed the Engine 46 crew to pull a preconnected hoseline off of Engine 31 and take it up the B/C stairway to the second floor. Shortly after that, Command radioed that he needed a backup line taken around to Side C. The Engine 46 FAO pulled the bumper lay off Engine 31 with the assistance of the Engine 31 FAO and advanced it around to the $\mathrm{C} / \mathrm{D}$ corner. Just as they reached the $\mathrm{C} / \mathrm{D}$ corner, the Engine 49 crew came out the exterior door on Side $\mathrm{C}$ and said they had been in a flashover. District Chief 1 arrived at the C/D corner and took the hoseline from the Engine 46 FAO and started to pull it along the Side $\mathrm{C}$ wall toward the fire apartment. District Chief 1 directed the Engine 46 FAO to go back to the apparatus and get the water flowing.

The Engine 46 lieutenant and two fire fighters advanced their hoseline up the B/C stairwell to the second floor and gave it to the Ladder $31 \mathrm{crew}$. The Heavy Rescue 9 fire fighter assisted the Ladder $31 \mathrm{crew}$ in advancing the hoseline into the fully involved fire apartment. They directed their hose stream toward the kitchen area. They could see another hose stream coming from outside through the patio door at Side C. The Ladder 31 lieutenant and fire fighter 1 both ran low on air so they gave the nozzle to the Heavy Rescue 9 fire fighter and went outside to get new air cylinders. The Heavy Rescue 


\section{Career Fire Apparatus Operator Died After Falling Down an Unsecured Elevator Shaft at a 5-Story Residential Apartment Building - Ohio}

9 fire fighter continued to work the nozzle in the fire apartment with the assistance of the Engine 46 crew.

The Ladder 31 lieutenant and fire fighter 1 heard a loud crashing sound as they were exiting the building. The fire was reported to be knocked down at approximately 0602 hours. The Heavy Rescue 9 fire fighter exited the fire apartment through the patio door to the exterior at Side C. He heard a Mayday on his radio stating that a fire fighter had fallen down an elevator shaft so he proceeded to Heavy Rescue 9 to meet his crew. The Engine 46 crew went back inside through the fire apartment to the second floor elevator door to assist with the extrication work to rescue the Heavy Rescue 14 FAO.

\section{Ladder 23 - Rapid Assistance Team “RAT”}

Ladder 23 with a crew of four (lieutenant, fire apparatus operator (FAO), 2 fire fighters) was dispatched on the first alarm as the Rapid Assistance Team (RAT). Ladder 23 arrived on scene at 0549 hours and was advised by Command that they would be going to work to back up Engine 46. They were instructed to pull a hoseline off Engine 49 to back up Engine 46 in the B/C stairwell and search the second floor. The Ladder 23 crew helped with the ladder rescue off the balcony of Apartment 26. They helped pull the backup hoseline up the B/C stairs to the second floor landing then searched Apartment 28. Two civilians were encountered and assisted in walking down the stairs to the outside. Then the Ladder 23 crew was instructed to search the $3^{\text {rd }}$ floor. The Ladder 23 crew heard the radio traffic about a mother and small child needing assistance in Apartment 57 so they climbed up the B/C stairs to the fifth floor where they met the Ladder 18 crew coming out of Apartment 57 with the occupants. Later, the Ladder 23 crew assisted with the extrication of the Heavy Rescue 14 FAO.

\section{Safety Officer}

The Shift Safety Officer position was staffed by a fire captain who was detailed to the Safety Officer (SO2) position for the shift. The SO2 arrived on-scene at 0553 hours and donned his gear. He then proceeded to the fire building and observed heavy smoke coming from the rear of the building. When SO2 arrived at the C/D corner, he observed fire fighters (Engine 49 and Engine 31 crews) coming out the exterior exit door on Side C. One of the fire fighters reported that a flashover had forced them to exit the second floor. SO2 radioed Command and reported that a flashover had forced both hoseline crews (Engine 49 and Engine 31) to exit the building. He observed heavy dark smoke coming out the Side $\mathrm{C}$ exterior door and also coming from the opposite end of the building. SO2 started to walk down Side $\mathrm{C}$ toward the fire apartment and observed fire blowing out of the patio doors. He radioed to the command that there was no water on the fire yet.

\section{Heavy Rescue 14}

Heavy Rescue 14 was dispatched on the second alarm at 0547 hours and arrived on scene at 0604 hours with a crew of four including an acting officer-in-charge (OIC), two fire fighters, and a fire apparatus operator (FAO - the victim). Note: The Heavy Rescue 14 FAO was a roving FAO within the district so he was not assigned to any particular crew. On this shift, he was assigned as the FAO on Heavy Rescue 14. The Heavy Rescue 14 officer was off duty on this shift so a senior fire fighter stepped up to serve as the acting officer-in-charge. 


\section{Career Fire Apparatus Operator Died After Falling Down an Unsecured Elevator Shaft at a 5-Story Residential Apartment Building - Ohio}

The Heavy Rescue 14 crew reported to Command once on scene and was immediately assigned to search the fifth floor. The Heavy Rescue 14 crew proceeded through the main lobby and started up the north stairwell near the B/C corner. According to their SCBA electronic data logger data, the OIC and the two fire fighters donned their SCBA masks and went on air in the stairway at approximately 0608 hours. The Heavy Rescue 14 FAO did not go on air at this time. They met District Chief 3, assigned as the Search and Rescue Operations Chief, while advancing to the fifth floor. District Chief 3 assigned Heavy Rescue 14 to go to Apartment 57 to initiate the rescue of a mother and small child reported to be in need of rescue. District Chief 3 radioed Command and informed him of this assignment. The Heavy Rescue 14 crew was in the B/C stairwell between the fourth and fifth floors at this time. The Heavy Rescue 14 OIC was in the lead, followed by the two Heavy Rescue 14 fire fighters, the Heavy Rescue 14 FAO, and District Chief 3 immediately behind the Heavy Rescue 14 FAO. At approximately 0610 hours, as the Heavy Rescue 14 crew was preparing to advance to the fifth floor, three fire fighters (Ladder 23 OIC, Ladder 23 fire fighter 1, and Ladder 18 fire fighter 1) started down the stairs with the mother and child. District Chief 3 radioed to Command that the mother and child were coming down the stairs. The Heavy Rescue 14 FAO went on air at this time (approximately 0610 hours). The rest of the Heavy Rescue 14 crew is believed to have already entered the fifth floor hallway at this time. They reported moderate smoke conditions with visibility limited to five feet or less. The Heavy Rescue 14 OIC and fire fighter 2 entered Apartment 57 and Heavy Rescue 14 fire fighter 1 entered Apartment 51 (see Diagram 1). The location of the Heavy Rescue 14 FAO could not be accounted for.

The Heavy Rescue 14 OIC, fire fighter 1 and fire fighter 2 met in the hallway after searching Apartments 51 and 57. The Heavy Rescue 14 OIC and fire fighter 1 entered Apartment 52 while Heavy Rescue 14 fire fighter 2 advanced down the hallway to the next door on the left (see Diagram 4). Heavy Rescue 14 fire fighter 2 observed that this door was different than the previous apartment doors he had entered. He pulled on the door handle and the door opened easily. Heavy Rescue 14 fire fighter 2 thought that something didn't seem right so he knelt down in the hallway and sounded the floor inside the door. He quickly realized that the door led to an open shaft. The Heavy Rescue 14 OIC and fire fighter 1 came out of Apartment 52 and met the Heavy Rescue 14 fire fighter 2. They discussed the open shaft. District Chief 3 (the Search and Rescue Operations Chief) met the Heavy Rescue 14 crew in front of the elevator door. The Heavy Rescue 14 fire fighter 2 used a permanent marker to write "Do Not Enter. Open Shaft" on the elevator door (see photo 8). The Heavy Rescue 14 FAO was not with the rest of the HR14 crew at this time. 


\section{Career Fire Apparatus Operator Died After Falling Down an Unsecured Elevator Shaft at a 5-Story Residential Apartment Building - Ohio}

The Ladder 32 OIC, Ladder 32 FAO, and Ladder 32 fire fighter 1 arrived on the fifth floor via the B/C stairway at approximately 00612 hours. They proceeded into Apartment 58 to rescue two civilian occupants from the balcony. Ladder 32 fire fighter 1 reported that as they were leading the two civilians from Apartment 58 into the hallway, they met the Heavy Rescue 14 FAO. The Heavy Rescue 14 FAO told the Ladder 32 crew that he was looking for the Heavy Rescue 14 crew. They reported that the Heavy Rescue 14 FAO identified himself by name to the Ladder 32 crew. The Ladder 32 crew proceeded to escort the two civilians down the $\mathrm{B} / \mathrm{C}$ stairs. It is believed that the Heavy Rescue 14 FAO advanced down the fifth floor hallway to find his crew. Note: This is the last known location of the Heavy Rescue 14 FAO before he was found in the elevator shaft. Diagram 4 shows the travel route taken by the Heavy Rescue 14 crew on the fifth floor.

The Heavy Rescue 14 FAO fell down the elevator shaft at approximately 0612 hours and became lodged in the narrow void between the rear of the elevator car and elevator shaft wall. At

approximately 0613 hours, the electronic incident command accountability system recorded the Heavy Rescue 14 FAO's PASS device motion alarm activating.

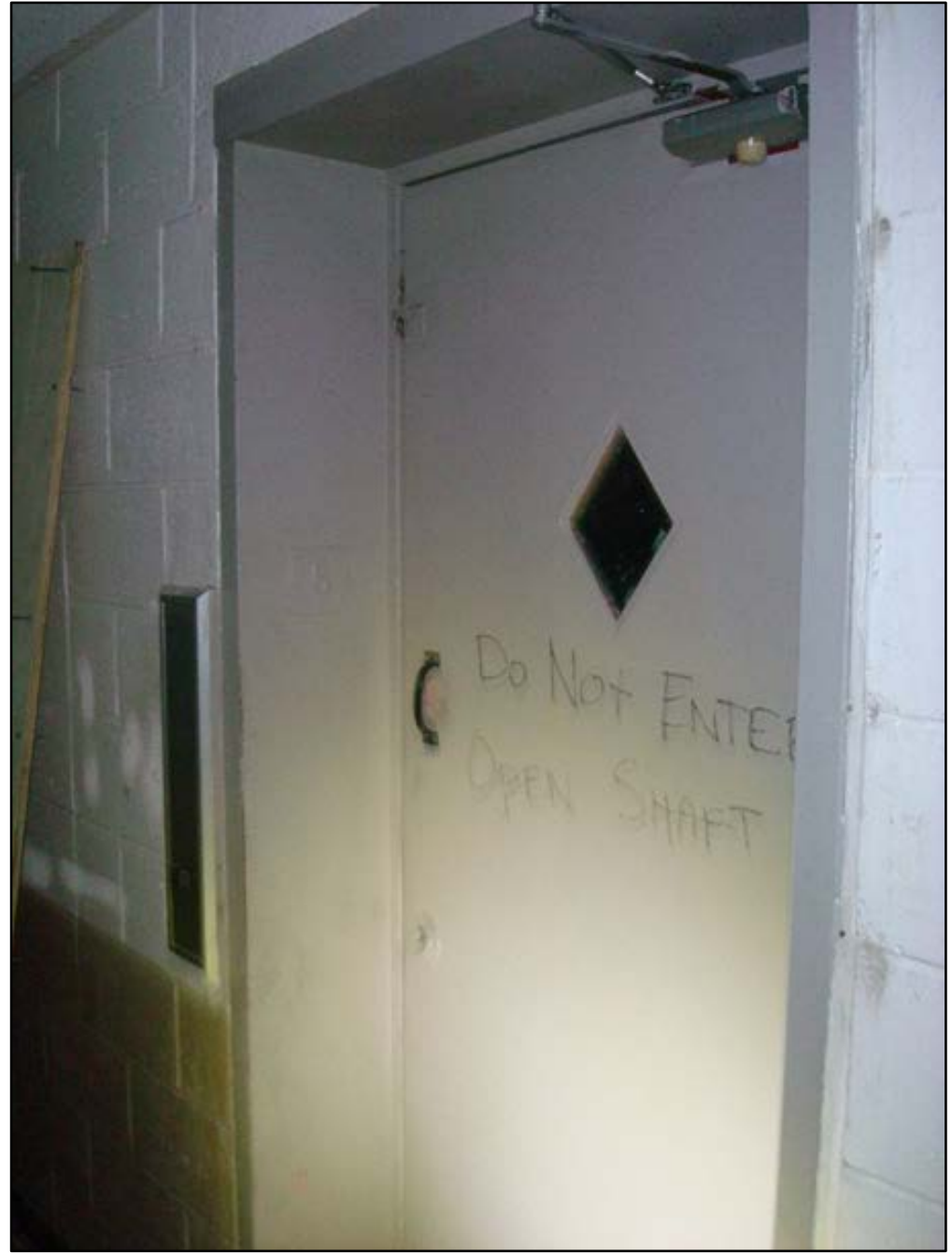

Photo 8. Fifth floor elevator hoistway door. Note warning written on door by Rescue $14 \mathrm{crew}$ member while searching the fifth floor. (Photo NIOSH) 
Career Fire Apparatus Operator Died After Falling Down an Unsecured Elevator Shaft at a 5-Story Residential Apartment Building - Ohio

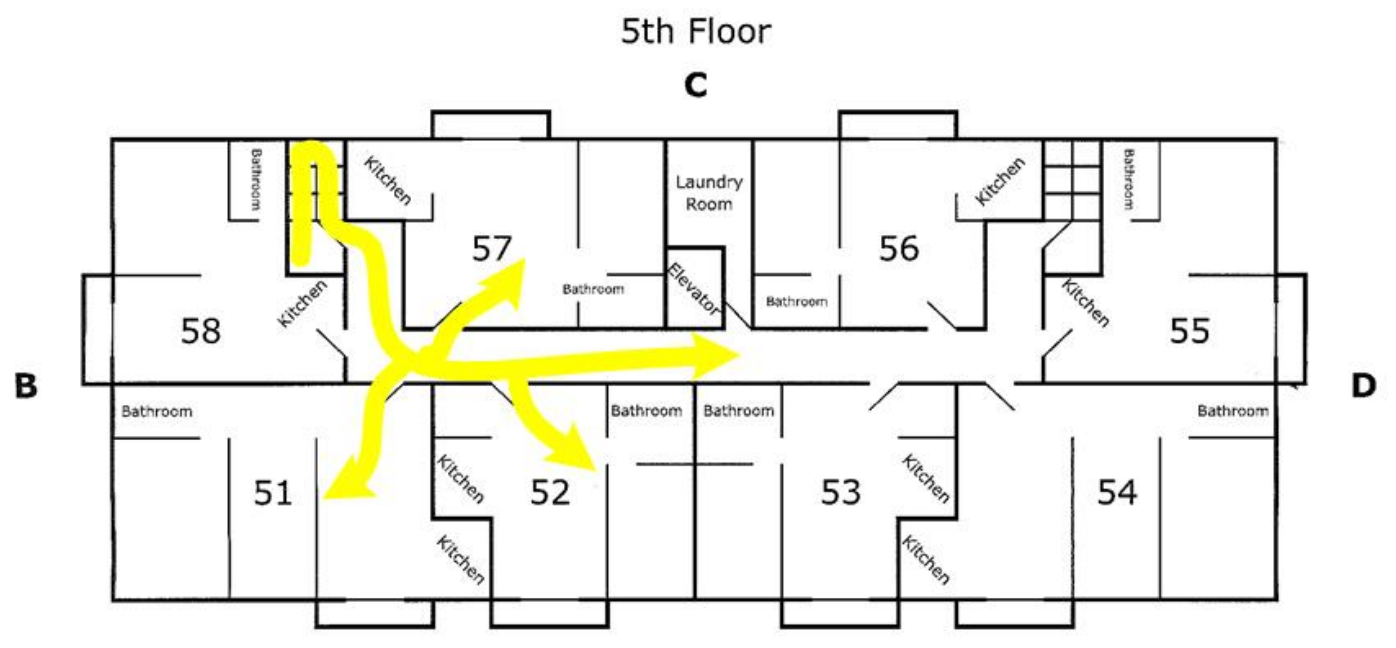

A

Diagram 4. Route followed by the Heavy Rescue $14 \mathrm{crew}$ as it advanced up the B/C stairwell to the fifth floor. The Heavy Rescue 14 officer-in-charge and fire fighter 2 searched Apartment 57 while Heavy Rescue 14 fire fighter 1 searched Apartment 51. They regrouped in the hallway and the Heavy Rescue 14 OIC and fire fighter 1 searched Apartment 52 while Heavy Rescue 14 fire fighter 2 proceeded down the hall and discovered the elevator hoistway door could be easily opened. The location of the Heavy Rescue 14 FAO was unknown during this time.

(Source NIOSH: Diagram adapted from floorplan provided by fire department.)

The Heavy Rescue 14 OIC, fire fighter 1 and fire fighter 2 met fire fighters from Engine 8 a short time later at the east end of the hallway near Apartment 55. The two crews discussed whether it was necessary to continue forcing open locked doors. The Engine 8 OIC radioed Command and requested verbal confirmation on the need to continue forcing open locked doors. The Heavy Rescue 14 OIC radioed Command that the fifth floor was all clear at approximately 0615 hours. 


\section{Career Fire Apparatus Operator Died After Falling Down an Unsecured Elevator Shaft at a 5-Story Residential Apartment Building - Ohio}

The Heavy Rescue 14 OIC initiated a personal accountability report (PAR) of the Heavy Rescue 14 crew and realized that the Heavy Rescue 14 FAO was not present. The Heavy Rescue 14 OIC, fire fighter 1, and fire fighter 2 began searching the apartments on the fifth floor looking for the missing Heavy Rescue 14 FAO, moving from Side D toward Side B.

Accountability had been delayed since Engine 46, the designated Safety and Accountability Company was deployed to assist in getting hoselines in place. Ladder 19, dispatched on the third alarm, was designated as Accountability while enroute. Ladder 19 arrived on scene at approximately 0614 hours and proceeded to the command post where the Ladder 31 captain riding with District Chief 4 was setting up the electronic accountability system in District Chief 4's vehicle. Command called for a PAR over the fireground radio channel at approximately 0619 hours.

The Heavy Rescue 14 OIC reported hearing an SCBA low air alarm bell sounding as the Heavy Rescue 14 crew neared the fifth floor elevator hoistway door. The Heavy Rescue 14 crew opened the elevator hoistway door and looked down the shaft where they observed a fire helmet on top of the elevator car some distance below. The time was approximately 0622 hours.

The Heavy Rescue 14 OIC radioed a Mayday but did not receive a reply. Some fire fighters reported hearing the Mayday over the radio. Others did not. The Heavy Rescue 14 OIC pushed the emergency button on his radio and then broadcast a Mayday for a fire fighter falling down the elevator shaft after several attempts to radio Mayday.

The Engine 49 fire fighter 1 met back up with the Heavy Rescue 9 FAO after retrieving another air cylinder and they proceeded to the fourth floor hallway and forced open the elevator hoistway door. They proceeded up to the fifth floor via the C/D stairwell where they encountered the Heavy Rescue 14 OIC opening apartment doors at the south end of the hallway. Following the Mayday, the Heavy Rescue 14 OIC directed the Engine 49 fire fighter 1 to stand at the fifth floor elevator door and guard it so that nobody else would fall down the shaft.

The Heavy Rescue 14 crew members rushed down the B/C steps to the third floor and forced open the elevator hoistway door. One of the Heavy Rescue 14 fire fighters jumped down onto the top of the elevator car as soon as the elevator door was opened. He told the Heavy Rescue 14 OIC that he could not reach the Heavy Rescue 14 FAO from his position on top of the car. The Heavy Rescue 14 FAO was wedged between the elevator car and the Side $C$ wall of the elevator shaft. It was quickly determined that the best way to extricate the Heavy Rescue 14 FAO was to open the second floor elevator hoistway door, get inside the elevator car, and cut through the back wall of the elevator car. The Special Operations Chief took charge of the rescue operation. Ventilation fans were set up to clear the smoke out of the elevator shaft. Fire fighters worked to cut through the elevator car using axes and hand tools so that they could access the space behind the elevator car. It took approximately 14 minutes from the time of the Mayday to free the Heavy Rescue 14 FAO. The Heavy Rescue 14 FAO was loaded onto a stokes basket and carried to the B/C stairway and then out the Side $\mathrm{C}$ doorway to the exterior. He was transported to a local hospital where he was pronounced dead. 


\section{Career Fire Apparatus Operator Died After Falling Down an Unsecured Elevator Shaft at a 5-Story Residential Apartment Building - Ohio}

\section{Fire Behavior}

Fire investigators determined that the origin and cause of this fire was accidential, caused by unattended cooking materials left on the stove. The fire originated on the second floor in Apartment 27 which was located on Side $\mathrm{C}$ and was caused by unattended cooking materials left on the stove at left rear (B/C corner) of the apartment (see Photo 9).

Key factors related to fire behavior and growth in this incident included:

- Automatic smoke detector activation at 0532 hours.

- Multiple phone calls to the Emergency Communications Center (ECC) reporting smoke in the building, building on fire, and civilians in need of rescue.

- Engine 49 (first due engine company) reported nothing showing upon arrival.

- Occupant of fire apartment told the Engine 49 crew that fire was in Apartment 27.

- Engine 49 fire fighter 1 followed occupant to the second floor to size up fire.

- Engine 49 fire fighter 1 reported having to don SCBA facepiece and go on air in second floor hallway due to smoke.

- Engine 49 fire fighter 1 reported door to Apartment 27 was hot to the touch.

- Engine 49 fire fighter 1 opened door and observed fire and heavy smoke inside apartment.

- Engine 49 fire fighter 1 closed door and returned outside with the occupant.

- District Chief 4 arrived on scene and confirmed working fire.

- Engine 49 OIC and fire fighter 2 directed to pull hoseline to second floor.

- Ladder 31 crew directed to vent sliding glass patio door at rear of fire apartment.

- Engine 49 hoseline crew encountered heavy smoke and heat in sccond floor hallway as they attempted to advance hoseline.

- Engine 49 crew unable to reach fire apartment with initial attack hose due to coupling snagging on stair tread in $\mathrm{C} / \mathrm{D}$ stairway.

- Heavy Rescue 9 crew reported fire blowing out apartment door from ceiling to floor when they arrived on second floor.

- Command directed Engine 31 to pull backup line to back up Engine 49 and also directed Engine 46 to pull hoseline to second floor to Ladder $31 \mathrm{crew}$.

- Ladder $31 \mathrm{crew}$ wedged open the B/C stairwell door leading to second floor.

- Command radioed Heavy Rescue 9 lieutenant to control the apartment door. Heavy Rescue 9 lieutenant attempted to close door with ceiling hook then replied to Command that door had already burned through.

- Extreme conditions forced Engine 49 and Engine 31 crews to retreat from second floor hallway.

- Fire apartment fully involved when Ladder 31 advanced hoseline into apartment.

- Smoke reported throughout apartment building on every floor.

- Moderate to heavy smoke on fifth floor (top floor of apartment building).

- Visibility on fifth floor reported to be less than five feet.

- Fire brought under control at 0602 hours. 


\section{Career Fire Apparatus Operator Died After Falling Down an Unsecured Elevator Shaft at a 5-Story Residential Apartment Building - Ohio}

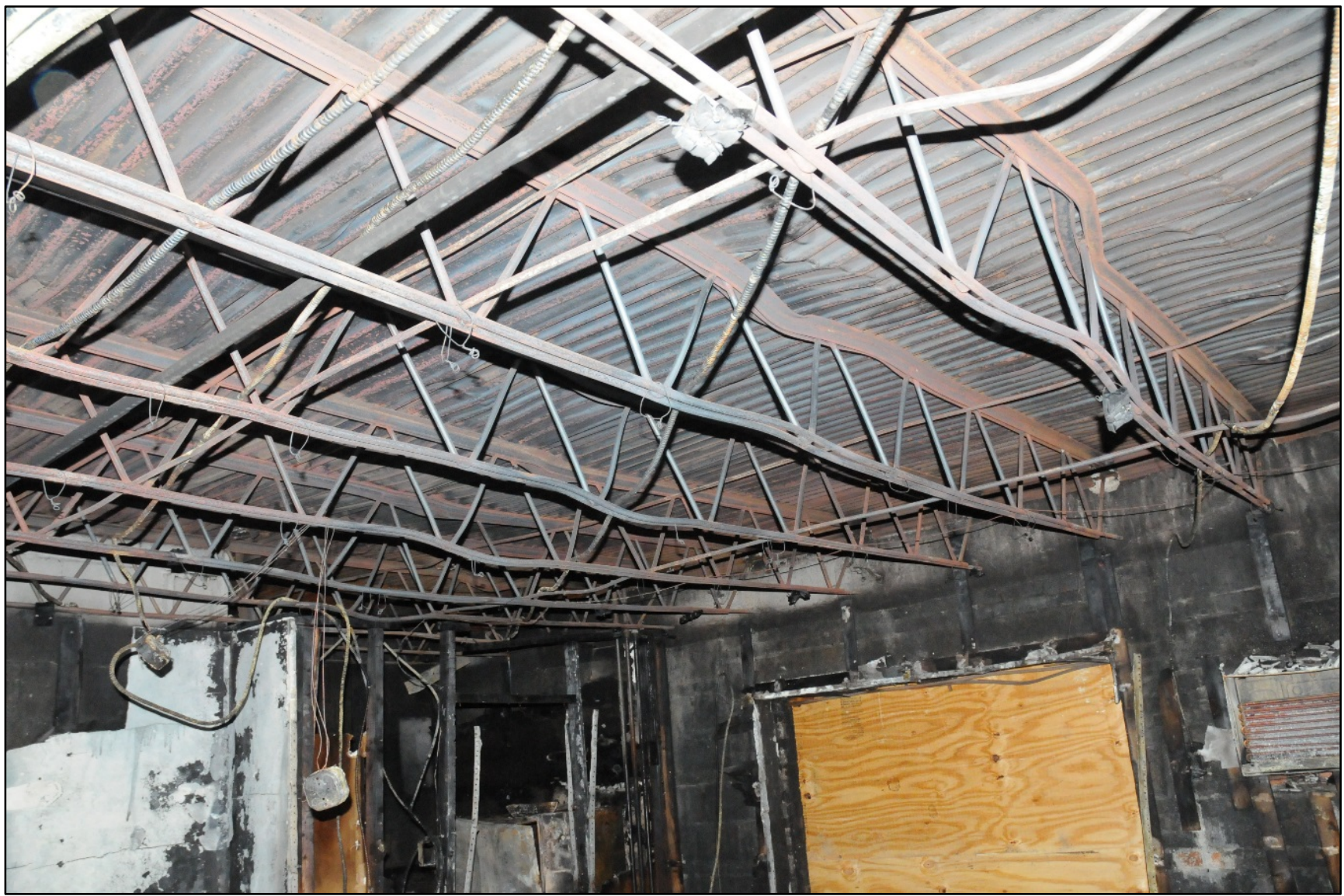

Photo 9. Interior of second floor apartment where fire originated. View is looking toward Side C. Plywood covers the opening where sliding glass doors opened to the ground level patio. The fire originated in the kitchen located on the left side of the photo. Note fire damaged metal bar joists indicating intensity of the fire.

(NIOSH photo.)

\section{Contributing Factors}

Occupational injuries and fatalities are often the result of one or more contributing factors or key events in a larger sequence of events that ultimately result in the injury or fatality. NIOSH investigators identified the following items as key contributing factors in this incident that ultimately led to the fatality:

- Breakdown in crew integrity

- Unsecured and unguarded elevator hoistway door

- Poor visibility due to moderate smoke conditions

- Delay in getting water onto the fire burning in a second floor apartment

- Acting officers in several key positions 


\section{Career Fire Apparatus Operator Died After Falling Down an Unsecured Elevator Shaft at a 5-Story Residential Apartment Building - Ohio}

- $\quad$ No standpipe or sprinkler system within the residential apartment building.

\section{Cause of Death}

According to the county coroner's report, the Heavy Rescue 14 FAO's cause of death was asphyxiation due to compression of the chest with fractures. The toxicology report was negative and blood carbon monoxide was listed at less than 5 percent.

\section{Recommendations}

Recommendation \#1: Fire departments should ensure that crew integrity is properly maintained by sight, voice, or radio contact when operating in an immediately dangerous to life and health (IDLH) atmosphere.

Discussion: Crews of fire fighters should operate as cohesive teams of at least two and remain in contact by visual (eye-to-eye contact), verbal (by radio or by person-to-person), or direct (by touch) contact when entering a structure or potentially hazardous area. NFPA 1500 Standard on Fire Department Occupational Safety and Health Program states in Paragraph 8.5.5, "Crew members operating in a hazardous area shall be in communication with each other through visual, audible, or physical means or safety guide rope, in order to coordinate their activities.” [NFPA 2013] Additionally, NFPA 1500 Paragraph 8.5.6 states, "Crew members shall be in proximity to each other to provide assistance in case of an emergency.” [NFPA 2013]

The International Association of Fire Chiefs, Safety, Health, and Survival Section has redefined the Rules of Engagement for Structural Fire-Fighting. One of the objectives is to ensure that fire fighters always enter a burning building as a team of two or more members and no fire fighter is allowed to be alone at any time while entering, operating in, or exiting a building. A critical element for fire fighter survival is crew integrity. Crew integrity means fire fighters stay together as a team of two or more. They must enter a structure together and remain together at all times while in the interior, and all members come out together. Crew integrity starts with the company officer ensuring that all members of the company understand their riding assignment, have the proper personal protective equipment, and have the proper tools. Crew integrity continues upon arrival at the incident, where the incident commander assigns tasks. The company officer communicates to the members of the company what their assignment is and how they will accomplish the assignment. Members of a company enter a hazardous environment together and should leave together to ensure that crew integrity is maintained. If one member has to leave, the whole company leaves together [IAFC 2012].

Every fire fighter is responsible for staying in communication with other crew members at all times. All fire fighters must maintain the unity of command by operating under the direction of the incident commander, division/group supervisor, or their company officer at all times. The ultimate responsibility for crew integrity (functioning as a team, ensuring no members get separated or lost) at the company level rests with the company officer. They must maintain constant contact with their assigned members by visual observation, voice, or touch while operating in a hazard zone. They must ensure they stay together as a company or crew. If any of these elements are not adhered to, crew integrity is lost and fire fighters are placed at great risk. If a fire fighter becomes separated and cannot 


\section{Career Fire Apparatus Operator Died After Falling Down an Unsecured Elevator Shaft at a 5-Story Residential Apartment Building - Ohio}

re-connect with his/her crew immediately, the fire fighter must attempt to communicate via portable radio with the company officer. If reconnection is not accomplished after three radio attempts or reconnection does not take place within 1 minute, a Mayday should be declared. The Mayday must be declared immediately if conditions are rapidly deteriorating. The fire fighter must next activate the radio's emergency alert button (where provided) followed by manually turning on the PASS alarm as part of a Mayday declaration. Similarly, if the company officer or the fire fighter's partner recognizes they have a separated member, they must immediately attempt to locate the member by using their radio or by voice. A Mayday must be declared immediately if contact is not established after three attempts or within 1 minute [IAFC 2012].

In this incident, there were a number of instances where crew integrity was not maintained. The Engine 49 fire fighter 1 left the crew and entered the structure with an occupant to investigate the fire. The Engine 49 OIC pulled the initial attack hoseline to the second floor hallway by himself before being joined by the Engine 49 fire fighter 2 who had connected their 5 -inch supply line to the hydrant. When the Heavy Rescue 9 crew advanced down the second floor hallway, one crew member stayed behind, then assisted the Ladder 31 crew on the hose line in the fire apartment. When the Heavy Rescue 14 crew advanced to the fifth floor to begin searching apartments, the Heavy Rescue 14 FAO became separated from the rest of the crew, later falling down the elevator shaft.

\section{Recommendations \# 2: Fire departments should ensure that an initial 360-degree size-up and risk assessment of the incident scene is completed as soon as possible to determine if interior fire- fighting operations are warranted.}

Discussion: Size-up involves gathering information and evaluating fireground factors. This assessment contributes to a decision-making process about the amount of risk that fire fighters will expose themselves to in order to bring the situation under control. The risk that fire fighters will face must be weighed against the potential to save savable lives and savable property. Today's modern fire environment demands a more thorough and accurate size-up. Lightweight construction and modern furnishings cause faster fire propagation, quicker time to flashover, shorter time to collapse, and reduced escape times for fire fighters and occupants. The fireground is unforgiving; there is little room for error. Fire fighters must evaluate at least four factors at every incident: building construction, smoke conditions, fire location and stage, and the survivability profile of potential occupants before deciding on a course of action.

A proper incident size-up begins when the alarm is received and it continues until the fire is under control. The on-scene size-up should include an evaluation of factors such as occupied or unoccupied structure, fire size, stage and location, access or barriers, estimated burn time, conditions on arrival, occupancy type, building construction and floor plan of the structure, fuel package, presence of combustible or hazardous materials, exposures, time of day, available staffing on scene or enroute, and weather conditions. Information on the structure should include size, construction type, age, condition (e.g., evidence of deterioration, weathering), renovations, construction features (lightweight, legacy, or a combination of both), loads on roof and walls (e.g., the presence of air conditioning units, ventilation ductwork, utility entrances), and available preplan information. Information obtained during size-up 


\section{Career Fire Apparatus Operator Died After Falling Down an Unsecured Elevator Shaft at a 5-Story Residential Apartment Building - Ohio}

allows the first arriving officer and subsequent arriving commanders to accurately determine the proper strategy to employ. The size-up should also include a continuous risk-versus-gain assessment, especially when benchmarks (e.g., primary search complete, fire knocked down) are met [IFSTA 2008; Dunn 2000; NIST, U.L. 2013].

NFPA 1500 Standard on Fire Department Occupational Safety and Health Program, section 8.3, provides detailed information regarding risk management during emergency operations [NFPA 2013]. The strategy and tactics of an incident are dictated by the size-up, initial risk assessment, and situational report by the first arriving officer. If physical barriers make the 360-degree size-up impractical for the first arriving officer, the size-up of Side Charlie should be delegated to another engine company or truck company. Interior fire fighting operations should not be initiated until an assessment of Side Charlie is completed and received by the incident commander, unless an obvious life safety issue exists (e.g., visible victims requiring immediate assistance). A radio report of conditions, including those on Side Charlie, should be transmitted over the assigned tactical channel. The transmission should be made using plain language and include the following:

- Civilian lives at risk (i.e., occupied or unoccupied) This information is critical to letting the responders know if they need to initiate an aggressive attack with the resources immediately on hand to save lives from the start or whether they have time to assemble and deploy resources more strategically for a more calculated attack on the fire.

- Smoke and fire conditions, with an emphasis on identifying the seat of the fire. The initial radio report from the first arriving unit for a structural fire should include the signal for a working fire, the number of stories, type of occupancy, and location of the fire. This information lays the foundation for additional reports and serves as notification to responding units as to type of SOPs to implement.

- Building occupancy type (e.g., residential, commercial, high-rise, industrial, etc.). This information aids in implementing or adjusting SOPs or planning necessary alternative actions.

- Building features (size, number of stories [particularly if there is a difference between Sides Alpha and Charlie], presence or absence of a basement, lightweight construction, presence of roof truss system, etc.).

- Initial action plan and strategy.

- Basement access.

- Any other safety hazards.

- Establishment of command using geographic or descriptive terms (e.g., "Main Street Command" or "Warehouse Command") and accountability. 


\section{Career Fire Apparatus Operator Died After Falling Down an Unsecured Elevator Shaft at a 5-Story Residential Apartment Building - Ohio}

Any change to operational priorities or responsibilities based on the above size-up shall be clearly communicated to Command, all responding units, and the dispatch center via the assigned tactical radio channel.

The initial size-up guides the first arriving officer's strategic and tactical decisions that will be used to bring the incident under control. The necessary tasks that need to occur at any fire regardless of the occupancy are: location of a water supply, an initial on-scene report upon arrival, an initial risk assessment, a follow-up situational report, deployment of hoselines and back-up hoselines, search and rescue tasks, ventilation, initial rapid intervention crews, ground and aerial ladder placement, fire attack and extinguishment, and salvage and overhaul. Over the past few years, fire fighters have adopted an acronym that details the initial steps to take when confronted with a working structure fire: SLICE-RS.

- $\quad$ Size up all scenes.

- Locate the fire.

- Identify and control the flow path (if possible).

- Cool the heated space from a safe location.

- Extinguish the fire.

- Rescue and Salvage, which are actions of opportunity that may occur at any time [Modern Fire Behavior 2014].

This incident is a stark reminder of how quickly fire situations develop in today's combustible environment and how many unresolved discrepancies emerge that impact decision-making. The initial dispatch was for an automatic alarm. Additional information upgraded the call to a working fire with reports of civilian residents in need of rescue as units responded. The first arriving engine company reported nothing showing, but was notified of the location of the fire by the apartment resident. The first due battalion chief was able to get a good view of three sides of the building (Side D, Side A, and Side B) as he drove into the parking lot and staged his vehicle north of the front entrance to the fivestory apartment building. A captain who was training to step up and act as a battalion chief was riding with the battalion chief on this shift. The captain immediately went to perform a 360-degree size-up, walking around Side B to Side C. The captain observed fire in the second-story apartment through the sliding glass patio doors at Side C. The sliding glass doors were knocked out which created a flow path for additional oxygen to feed the fire as crews worked to get hoselines in place.

\section{Recommendation \#3: Fire departments should train and empower all fire fighters to report unsafe conditions to incident command.}

Discussion: The International Association of Fire Chiefs (IAFC), Safety, Health and Survival section developed the "Rules of Engagement for Structural Fire Fighting." The rules of engagement have been developed to assist both the fire fighter and incident commander (as well as command team officers) in risk assessment and "Go or No-Go" decisions. The fire ground creates a significant risk to fire fighters. It is the responsibility of the incident commander and command organization officers to minimize fire fighter exposure to unsafe conditions and stop unsafe practices [IAFC 2012]. 


\section{Career Fire Apparatus Operator Died After Falling Down an Unsecured Elevator Shaft at a 5-Story Residential Apartment Building - Ohio}

The IAFC Rules of Engagement can assist the incident commander, company officers, and fire fighters in assessing their situational awareness. One principle applied in the rules of engagement is that fire fighters and the company officers are the members most at risk for injury or death and will be the first to identify unsafe conditions and practices. The rules integrate the fire fighter into the risk assessment decision-making process. These members should be the ultimate decision makers as to whether it's safe to proceed with assigned objectives. The rules allow a process for that decision to be made where it is not safe to proceed, while still maintaining command unity and discipline.

One of the IAFC Rules of Engagement for Firefighter Survival states: "You Are Required to Report Unsafe Practices or Conditions That Can Harm You. Stop, Evaluate, and Decide.” This rule applies the principles of crew resource management by encouraging all fire fighters to maintain heightened situational awareness, and be responsible for their own safety and that of other firefighters. All firefighters become the additional eyes and ears of the incident commander and should alert the incident commander (or the immediate supervisor) to unacceptable situations. No fire attack or building is worth the life of a firefighter or a preventable (potentially career ending) injury. The intent of this rule is to allow any member to report a safety concern through a structured process without fear of penalty.

One of the key tenants of the National Fallen Firefighter Foundation (NFFF) is their 16 Firefighter Life Safety Initiatives. The 16 Initiatives (FLSI) were jointly developed by representatives of the major fire service constituencies in 2004 at a Firefighter Safety Summit in Tampa, Florida. Summit attendees tasked the National Fallen Firefighters Foundation with promulgating the Initiatives throughout the fire service, and developing material to support their implementation [NFFF 2004a].

Life Safety Initiative Number 4 is "Empowerment - All firefighters must be empowered to stop unsafe practices." While this may appear to be a challenging or even controversial statement, it simply means that every organization should provide an environment that allows its members to speak up regarding personal and organizational safety, without negative consequences for doing so (within a prescribed context) and without decentralizing the authority of the formal leader. The goal is to have every member fully engaged during an emergency incident with a focus on doing the work in a proficient manner and looking out for one another to avoid injuries and potential line-of-duty deaths [NFFF 2004b].

Every fire fighter is responsible for their individual safety and the safety of other fire fighters. Each fire fighter is responsible for identifying risks and hazards and reporting the hazards to supervisors. Supervisors are responsible for accepting reports regarding safety concerns without penalizing the firefighter and properly acting on the report to ensure the safety of fire fighters.

In this incident, the Heavy Rescue 14 fire fighter 2 recognized the unlocked elevator hoistway door and open elevator shaft as a hazard. He reported this information to the Heavy Rescue 14 OIC and Heavy Rescue 14 fire fighter 1. The Heavy Rescue 14 fire fighter 2 wrote "Do Not Enter Open Shaft" on the elevator hoistway door with a permanent marker. The Heavy Rescue 14 crew reported this information to the Search and Rescue Operations Chief (District Chief 3) and other fire fighters 


\section{Career Fire Apparatus Operator Died After Falling Down an Unsecured Elevator Shaft at a 5-Story Residential Apartment Building - Ohio}

who were on the fifth floor at the time but this information was never reported to incident command or the shift safety officer. The Heavy Rescue 14 FAO was unaccounted for during this time. A radio transmission to Command advising Command of the open shaft hazard could potentially have alerted the Heavy Rescue 14 FAO. This information could have allowed the incident commander and/or the shift safety officer to take action to prevent exposure to this hazard by establishing a hazard control zone restricting access to the elevator hoistway door. Shortly after the Heavy Rescue $14 \mathrm{crew}$ discovered the unlocked elevator hoistway door and notified other fire fighters of what they encountered on the fifth floor, the unaccounted for Heavy Rescue 14 FAO fell down the elevator shaft.

\section{Recommendation \#4: Fire departments should ensure that appropriate staffing levels are available on scene to accomplish fireground tasks and be available for unexpected emergencies.}

Discussion: Adequate resources are needed at incident scenes to ensure rapid incident stabilization and to promote fire fighter safety and health. A department should pre-plan the tasks that may be performed at any structural fire prior to response and develop response packages to address the tasks. From determining the required fire flow, to stretching hoselines, forcing entry, search, rescue, extinguishment and much more, fire departments should consider what the staffing need are in order to simultaneously perform these tasks. The planning for the first-alarm assignment needs to include sufficient additional unassigned fire fighters to be on scene, staged and ready to assist with fireground operations in the event of an emergency or to allow for on-scene fire fighter rehabilitation. Incident commanders should recognize the limits of available resources to complete fireground tasks and adjust their desired action plan to coincide with resources on hand.

NFPA 1710 Standard for the Organization and Deployment of Fire Suppression Operations, Emergency Medical Operations, and Special Operations to the Public by Career Fire Departments identifies the minimum resources for an effective firefighting force to perform critical tasks. These tasks include establishing water supply, deploying an initial attack line, ventilating, performing search and rescue, and establishing a rapid intervention team or RIT. NFPA 1710 recommends that the minimum staffing level for an engine company to perform effective and efficient fire suppression tasks is four fire fighters. However, NFPA 1710 also recommends that large jurisdictions with tactical hazards, high hazard occupancies, high incident frequencies, or other pertinent factors, should staff companies with a minimum of five or six on-duty members [NFPA 2016].

In addition, a study released by the National Institute for Standards and Technology (NIST), Report on Residential Fireground Field Experiments, concluded that a three-person crew started and completed a primary search and rescue $25 \%$ faster than a two-person crew and that a four or five-person crew started and completed a primary search and rescue 6\% faster than a three-person crew [NIST 2010].

In this incident, the fire department responded with four-person crews on both engine and ladder companies. Three engine companies, three ladder companies, and a five-person heavy rescue company responded to the five-story residential apartment building fire on the first alarm. The size and location of the structure, along with the number of civilian occupants in need of rescue stretched the available resources beyond their normal assignments. The incident commander needed the Safety and 


\section{Career Fire Apparatus Operator Died After Falling Down an Unsecured Elevator Shaft at a 5-Story Residential Apartment Building - Ohio}

Accountability Company (Engine 46) and the Rapid Assistance Team (Ladder 23) to perform necessary tasks on the fireground such as pulling additional hoselines and backing up the initial hoseline companies. This resulted in a delay in establishing fireground accountability and crews operating without a dedicated Rapid Assistance Team in place.

\section{Recommendation \#5: Fire departments should review standard operating procedures used to account for all fire fighters and first responders assigned to an incident.}

Discussion: A personnel accountability system is a system that readily identifies both the location and function of all members operating at an incident scene. [NFPA 2013, NFPA 2014] The philosophy of the personnel accountability system starts with the same principles of an incident management system company unity and unity of command. Accountability can be fulfilled initially and maintained throughout the incident by documenting the situation status and resource status on a tactical worksheet.

One of the most important functions of "Command Safety" is for the incident commander to initiate an accountability system that includes the functional and geographical assignments at the beginning of operations until the termination of the incident. It is very important for the first on-scene officer to initiate an accountability system. This initial system promotes the efficient passing or transfer of information to the next officer who assumes “Command” upon arrival. [NFPA 2014]

A functional personnel accountability system requires the following:

- Development and implementation of a departmental SOP

- Necessary components and hardware

- Training and education program including practical applications for all members on the operation of the system

- Strict enforcement during emergency incidents.

There are many different methods and tools for resource accountability. Some examples are:

- Electronic accountability system

- Tactical worksheets

- Command boards

- Apparatus riding lists

- Company responding boards

- Electronic bar-coding systems

- Accountability tags or keys (e.g., PASSPORT System) [NFPA 2014].

The accountability process may have to be assigned to an Accountability Group at a large scale incident such as this. Each division and group would be responsible for maintaining the accountability of all members assigned to their division and group. This would be very similar to the accountability process used during high-rise fire-fighting operations. The personnel accountability system should comply with the requirements of NFPA 1561 Standard on Emergency Services Incident Management System and Command Safety [NFPA 2014]. 


\section{Career Fire Apparatus Operator Died After Falling Down an Unsecured Elevator Shaft at a 5-Story Residential Apartment Building - Ohio}

The fire department involved in this incident uses a fireground electronic accountability system (EAS) produced by the manufacturer of their self-contained breathing apparatus. The EAS is built into the personal alert safety system and transmits to a computerized electronic control panel and display in the district chief's vehicle. This system must be activated at the control panel at the start of an emergency operation. This department's procedure calls for the third-due engine company to be the designated Safety and Accountability Company. The Safety and Accountability Company sets up the EAS as soon as they arrive on scene. In this incident, the incident commander needed the Safety and Accountability Company (Engine 46) to work pulling hoselines due to the number of occupants and fire progression. A Safety and Accountability Company was not designated until a third alarm company (Ladder 19) was designated as the Safety and Accountability Company.

\section{Recommendation \#6: Fire departments should provide chief officers with a staff assistant or chief's aide to support Command Safety and realize the benefits of a command team.}

Discussion: A chief's aide, staff assistant, or command incident technician is a position designed to assist an incident commander with various operational duties during emergency incidents. The chief's aide is an essential element for effective incident management. The staff assistant can assist with key functions. These functions include: managing the tactical worksheet; maintaining personnel accountability of all members operating at the incident including resource status and deployment location; monitoring radio communications on the dispatch, command, and fireground channels; controlling information flow by computer, fax, or telephone; and accessing reference material and preincident plans [LAFD 2011].

The incident commander and members who are assigned a supervisory responsibility that involves three or more companies or crews under their command should have an additional person (staff aide) assigned to facilitate the tracking and accountability of the assigned companies or crews. One of the essential functions or responsibilities of a chief's aide is to manage the personnel accountability system, a vital component of the fire fighter safety process. Accountability on the fireground can be maintained in a variety of methods. The intent is to have a functional system that is designed to account and track personnel as they perform their fireground tasks. The chief's aide uses this system to provide a rapid accounting of all responders at the incident in the event of an emergency or Mayday.

Chief Officers are required to respond quickly to emergency incidents. They have to be fully aware of heavy traffic conditions, construction detours, traffic signals, and other conditions in their response route. More importantly, the chief officer must also monitor and comprehend radio traffic from responding units to assess which companies are responding and/or on scene, develop a strategy for the incident based upon input from first-arriving officers, and develop and communicate an incident action plan that defines the strategy of the incident. A chief's aide is invaluable in assisting the battalion chief or chief officer in processing information without distraction and can complete the necessary tasks enroute to the scene. [Ciarrocca and Harms 2011] 


\section{Career Fire Apparatus Operator Died After Falling Down an Unsecured Elevator Shaft at a 5-Story Residential Apartment Building - Ohio}

Departments should consider the chief's aide to be an individual who has the experience and authority to conduct the required tasks. Other potential roles for the chief's aide include assisting with the initial size-up, completing a 360-degree size-up, coordinating progress reports from division/group officers, maintaining the tactical worksheet or accountability system, functioning as the initial scene safety officer, and other functions identified by the incident commander. The aide position can be used as a training position to help facilitate officer development. There are also non-emergency functions the chief's aide performs that are vital to the daily operations of the department. Chief's aides are assigned to command officers to perform daily administration functions such as position staffing and leave management.

At this incident, the incident commander did not have the benefit of a regularly assigned staff assistant to manage the personnel accountability system and assist with communications, tactical worksheets and other duties. A senior captain was riding with District Chief 4 on the day of the incident, training to act as a district chief. When they arrived on scene, the senior captain proceeded to conduct a 360degree size up while District Chief 4 set up the command post and assumed command. The third-due engine was designated as the Safety and Accountability Company per standard operating procedures but due to the delay in getting the initial attack hoseline to the fire apartment, the incident commander made the decision to put both Rapid Assistance Team (Ladder 23) and the Safety and Accountability Company (Engine 46) crews to work. This resulted in a delay in establishing fireground accountability. A personnel accountability report was not taken until approximately 40 minutes after crews were on scene.

\section{Recommendation \#7: Fire departments should ensure that interior attack crews always enter a hazardous environment with a charged hoseline.}

Discussion: The modern fire environment changes very rapidly, often without warning. Modern fuel packages have changed and industry standards do not permit entry into this environment without a charged hoseline except in life-saving situations. Many fire fighters have advocated this tactical method based on previous years of experiencing successful results. Fire fighters entering the hazardous atmosphere should be prepared to rapidly apply water when interior temperatures increase, often without warning.

The fire service needs to re-evaluate generationally passed-down standard operating procedures against current research about the modern fire environment [NIST, UL 2013; Modern Fire Behavior 2014]. The speed of temperature changes in the modern fire environment are calling into question the wisdom of advancing uncharged hoselines into smoke-charged, IDLH atmospheres. The risks of ignoring recommendations has been identified in the Normalization of Deviance presentation series by Colonel Mike Mullane, retired USAF. Just because fire crews have not experienced an adverse thermal assault advancing an uncharged hoseline into an IDLH atmosphere does not solidify the safety of the practice [Mullane 2009].

Fundamental firefighting tactics dictate that the fire hose is charged before entering a burning building. Because it can be difficult to drag a charged hoseline up stairways, around corners, through doorways 


\section{Career Fire Apparatus Operator Died After Falling Down an Unsecured Elevator Shaft at a 5-Story Residential Apartment Building - Ohio}

and around obstacles, the hoseline should be advanced up stairways uncharged when conditions allow [IFSTA 2008]. However, numerous fire fighters have been exposed to rapidly changing fire conditions because they advanced too far with the uncharged hoseline or were unaware the uncharged hoseline was wedged or pinched behind them. When advancing hose into a structure, fire fighters need to be aware of the hazards and potential dangers of fire dynamics. These dangers include flowpath, ventilation limited fires and fire conditions that will change faster than a fire fighter can react. Fire fighters operating in limited visibility atmospheres without a charged hoseline have advanced too far into the structure.

In this incident, the Engine 49 OIC pulled the uncharged hoseline up the stairs to the second floor and advanced down the hallway toward the fire apartment. He advanced until he could no longer pull the hose. Unknown to him, a hose coupling had snagged between a stair tread and the wall in the stairway. He radioed for water as the Engine 49 fire fighter 2 was following the hoseline inside to meet him. Fire conditions rapidly deteriorated in the hallway before water arrived at the nozzle and the Engine 49 crew was forced to retreat before applying water. This delay in getting water onto the fire contributed to the smoke conditions on all floors of the five-story apartment building. Crews operating on the fifth floor reported visibility to be 5 feet or less at the approximate time that the Heavy Rescue 14 FAO fell down the elevator shaft.

Recommendation \#8: Fire departments should ensure that all fire fighters, company officers, and chief officers are trained in and follow proper radio discipline while operating at emergency incidents.

Discussion: One of the keys to both the success of fireground operations and to the safety of fire fighters performing those operations is effective communication [IFSTA 2008]. The NIOSH Fire Fighter Fatality Investigation and Prevention Program has identified a number of recent fatal incidents in which ineffective radio fireground communications was identified as a contributing factor [NIOSH 2009a, NIOSH 2009b, NIOSH 2011a, NIOSH 2011b, NIOSH 2012].

Several recent incidents involving fire fighter fatalities where inadequate fireground communications were identified as contributing factors to the injuries and deaths prompted the U.S. Fire Administration (USFA) to study the potential causes of communication breakdown and to provide recommendations that would help departments improve operational communications. As with any tool, fire fighters need to receive training in proper operation, routine preventative maintenance, and limitations of the portable radio used by the department. Radio discipline is vital for effective communication among firefighters, dispatchers, and other emergency personnel. Systems with inadequate capacities can become quickly overwhelmed even during routine incidents, seriously compromising fire fighter safety. Allowing unlimited message transmission may create a situation where vital messages cannot be heard due to the number of less important transmissions being broadcast. By contrast, restricting radio traffic to only "vital” messages may prevent important information from being broadcast. The challenge is achieving a balance to ensure that all potentially important information is broadcast, but not at the expense of emergency transmissions or Mayday calls from interior crews. The best way to develop good listening and speaking skills is through training and continued practice during multi- 


\section{Career Fire Apparatus Operator Died After Falling Down an Unsecured Elevator Shaft at a 5-Story Residential Apartment Building - Ohio}

company operations drills or simulations. It may also be helpful for command or training officers to use tapes of actually incidents, or drills, to critique procedures and reinforce the importance of these skills [USFA 1999].

There are several actions fire fighters can take to improve radio discipline. An obvious way is to not use radios for communicating when face-to-face dialogue is a better and available choice. Examples of these situations include: when the sender and receiver are located a short distance from one another, when conferring about strategic or tactical options, or when a complex, vital message (such as a change in strategy from offensive to defensive) must be conveyed. Face-to-face communication is generally more effective than radio communication since both sender and receiver have the added benefit of being able to see and interpret non-verbal cues that support conveying ideas or understanding (e.g., eye contact, physical contact, body language). Distractions are also reduced and people can ask questions or identify problems more readily during one-on-one dialogue. Command officers can use runners to deliver and obtain information from remote units. Using a runner has the potential added benefit of providing another view of the situation to the incident commander [USFA 1999].

A related issue is the tendency for fire fighters to not report problems completing an assignment; for example, forcing entry, procuring a water supply, or searching the fire floor. Fire fighters sometimes are reluctant to report difficulties for fear of being judged as slow, incompetent, or unaggressive, all of which are contradictory to the fire department cultural values. Radio discipline, while important must achieve a balance between limiting non-essential radio traffic and ensuring that potentially important information is regularly broadcast. Fire departments need to ensure that training is conducted to develop effective fire fighter communication skills [USFA 1999].

In this incident, a number of radio discipline and fireground communication issues were revealed during interviews. Multiple fire fighters, including chief officers, reported being on the wrong radio channel. Fire fighters also reported not hearing critical radio communications and not being able to transmit at critical times. The incident commander reported receiving important information from some interior crews while not receiving information from others. The chief officer in the Charlie Sector reported requesting a hose line was needed at the rear patio door to the fire apartment, but he was not broadcasting over the tactical fireground channel. This resulted in the chief officer walking to the C/D corner and retrieving an uncharged hoseline by himself and directing a fire fighter to go charge the line. The chief officer worked the hoseline by himself until fire fighters could be sent to take over the hose line operations.

Recommendation \#9: Fire departments should integrate current fire behavior research findings developed by the National Institute of Standards and Technology (NIST) and Underwriter's Laboratories (UL) into operational procedures by developing or updating standard operating procedures, conducting live fire training, and revising fireground tactics.

Discussion: The National Institute of Standards and Technology (NIST) and Underwriters Laboratories (UL) have conducted a multi-year series of live burn experiments designed to replicate conditions in 


\section{Career Fire Apparatus Operator Died After Falling Down an Unsecured Elevator Shaft at a 5-Story Residential Apartment Building - Ohio}

modern homes and residential structures to validate previous testing done in laboratory settings. The results of these experiments provide fire fighters with assessment tools to better recognize, predict, and react to fires involving new materials and construction. The fire research experiments were conducted in cooperation with the Fire Department of New York, Chicago Fire Department, Spartanburg South Carolina Fire and Rescue, and other agencies. The live burn tests are aimed at quantifying emerging theories about how fires are different today, largely due to new building construction and the composition of home furnishings and products. In the past, these products were mainly composed of natural materials, such as wood and cotton. Today's products contain large quantities of petroleumbased products and synthetic materials that burn faster and hotter and generate large volumes of fuelrich smoke. Where a fire in a room once took approximately 20 minutes to flashover - igniting all the contents - today's furnished rooms reaches flashover in as little as 4 to 5 minutes [NIST, UL 2013].

Modern living spaces tend to be more open, less compartmentalized and better insulated than homes built years ago. As a result, interior residential fires can generate oxygen-depleted, fuel-rich environments within minutes. This fire condition of hot, fuel-rich smoke is highly reactive to the introduction of oxygen. Opening a door or venting a window introduces massive quantities of oxygen to this environment which promotes explosive and rapid transition to flashover. These same conditions can occur in commercial structures as seen in the fire at the Charleston, South Carolina, Sofa Super Store [NIOSH 2009a].

The NIST and UL experiments evaluated individual and combinations of methods for strategically ventilating and isolating fires to delay and/or prevent flashover. In contrast, kicking a door open or breaking a window (particularly large surface windows like panes found in sliding glass doors) without knowledge of conditions inside creates a portal for air that introduces immense quantities of oxygen into an oxygen-limited, high-heat, fuel-rich, fire environment.

Fire suppression operations have traditionally been conducted using the interior attack as a means to reduce water damage and limit fire damage to structures. These operations must be coordinated with ventilation operations to reduce the risk to fire fighters working in the interior. Previous research and examinations of line-of-duty deaths have shown that uncoordinated ventilation events occurring with fire fighters in the structure prior to suppression have led to tragic results [NIOSH 2009a, NIOSH 2012, NIOSH 2013]. One means of eliminating the possibilities of this occurrence is the use of a transitional attack. The transitional attack directs a fire stream into the structure from the exterior to cool superheated fire gases and reduce the heat release rate of the fire prior to the fire fighters entering the building. Two major concerns with the transitional attack are the potential harm that might occur to people trapped in the structure and the amount of water damage to the structure. Further research is needed to document the changes of the thermal environment within the structure and the impact on the viability of people who might be trapped in the structure [NIST, UL 2013].

Based upon the NIST and UL research, the following actions regarding critical fireground operations should be taken into account at every fire scene: 


\section{Career Fire Apparatus Operator Died After Falling Down an Unsecured Elevator Shaft at a 5-Story Residential Apartment Building - Ohio}

- Size-up

Size-up must be performed at every fire. Consideration must be given to situational conditions, such as occupied or unoccupied structure, fire location and size of the fire, building contents, construction features, weather and resources available. Ensure a 360-degree size-up is conducted whenever possible. A tactical plan must be developed, communicated, and implemented in an organized and disciplined manner for each fire.

\section{- Ventilation}

Fire departments need to manage and control openings in structures during firefighting operations. All ventilation must be coordinated with suppression activities. Uncontrolled ventilation introduces large volumes of oxygen into the structure, resulting in a rapid increase in fire development. This increased heat release rate elevates the risk of burns to fire fighters caught in the flow path. Limiting fire growth, fire spread, controlling the flow path of inlet air and flow of fire gases during tactical operations are critical actions that reduce fire fighter exposure to untenable conditions.

- Fire-fighting Operations

Water should be applied to the fire as soon as possible given the fuel-rich, high heat-release environment the fire service operates in today. Water application through an exterior opening into the fire compartment may be the best first action fire fighters take before entering the structure to conduct an interior attack.

Fire attack teams should cool the interior spaces of a fire building during the fire attack. Water application from the safest location possible prior to committing personnel into smoldering, ventilation-limited, or fully developed spaces reduces risk and control fires more effectively.

\section{- Rapid Intervention}

Fire department rapid intervention procedures should be updated to include putting water on the fire as soon as possible and controlling ventilation openings during fire fighter Mayday incidents [ISFSI 2013].

In this incident the Engine 49 fire fighter 1 followed the occupant of the fire apartment to the second floor, quickly looked inside to check the conditions, and then closed the door and returned outside. Uncontrolled ventilation was initiated when the sliding glass patio door was knocked out, allowing a massive quantity of air to enter the fire apartment, further feeding the fire. The delay in getting water onto the fire allowed the fire to rapidly grow until the apartment was fully involved. The fire growth could have been delayed if the patio door had remained intact as the fire would have reached a ventilation limited state. The fire was extending into the second floor hallway when Heavy Rescue 9 arrived on the second floor. Both stairwell doors to the second floor were blocked open for hoseline access. Controlling these stairwell doors would have helped to limit the in-rush of fresh air. Fire departments should consider adapting modern fire behavior tactics as part of their overall incident management plan. Recent research by NIST, Underwriters Laboratories and others has shown that 


\section{Career Fire Apparatus Operator Died After Falling Down an Unsecured Elevator Shaft at a 5-Story Residential Apartment Building - Ohio}

limiting ventilation openings and coordinating hoseline deployment/water application with controlled ventilation can reduce interior temperatures. This temperature reduction makes interior conditions safer for both occupants and fire fighters [NIST, UL 2013].

Recommendation \#10: Fire departments should ensure that tools, equipment and supplies used during emergency responses are adequate for their intended use.

Discussion: Paramedics and fire fighter/EMTs who assisted with emergency fireground treatment for the Heavy Rescue 14 FAO reported having trouble cutting through his turnout clothing during this incident. The rescue shears being used were too small or not sharp enough to cut through heavy turnout clothing. This has been reported to NIOSH in other recent investigations (pending NIOSH reports F2015-13 and F2015-18). Fire departments need to ensure that all tools, equipment and supplies used during emergency responses are adequate and suitable for their intended uses before they are needed in an emergency situation.

\section{Recommendation \#11: Fire departments should consider ways to block open shafts and fall hazard} areas when they are identified.

Discussion: Fall hazards identified during emergency operations need to be immediately reported to other fire fighters working in the area and the incident commander. The hazard area should be blocked off to reduce the possibility of a fall. Pieces of furniture can be used to cover or block a hole in a floor, open shaft, or stairway. A door can be removed from its hinges and used to cover a hole or block access to an open shaft. If sufficient staffing is present and the immediate area is safe, a fire fighter can be stationed at the fall hazard area to ensure that other fire fighters do not fall.

In this incident, the unsecured hoistway door to the elevator shaft was marked with the warning "Do Not Enter, Open Shaft." A fire fighter was stationed at the elevator door on the $5^{\text {th }}$ floor to prevent the possibility of other fire fighters opening the elevator door after it was realized that the Heavy Rescue 14 FAO had fallen down the elevator shaft.

Recommendation \#12: State, local and municipal governments, building owners, and authorities having jurisdiction should consider requiring sprinkler systems be installed in multi-family housing units.

Discussion: Fire development beyond the incipient stage is one of the greatest hazards that fire fighters face in today's combustible environment. This exposure and risk to fire fighters can be dramatically reduced when fires are controlled or extinguished by automatic sprinkler systems. NFPA statistics show that most fires in sprinklered buildings are controlled prior to fire department arrival by the activation of one or two sprinkler heads. The presence of automatic fire sprinklers also reduces the exposure risk to fire fighters in rescue situations by allowing the safe egress of building occupants before the fire department arrives on scene. Finally, the exposure to hazards such as building collapse and overhaul operations are greatly reduced, if not eliminated, when fire development is arrested and controlled. 


\section{Career Fire Apparatus Operator Died After Falling Down an Unsecured Elevator Shaft at a 5-Story Residential Apartment Building - Ohio}

The five-story residential apartment building involved in this incident was constructed in 1962 . The fire and building codes at that time did not require a sprinkler system. A sprinkler system in the apartment of origin would likely have contained the fire to the kitchen, if not extinguished the fire completely. A quick-action sprinkler containing or extinguishing the fire would have significantly reduced the risk to all and likely would have prevented this fatality and the civilian and fire fighter injuries.

\section{References}

Ciarrocca M, Harms T [2011]. Help on the scene. Fire Rescue Magazine 29(2):40-48.

Dunn V [2000]. Command and control of fires and emergencies. Saddle Brook, NJ: Fire Engineering Book and Videos.

IAFC [2012]. Rules of engagement for structural firefighting. Increasing Firefighter Survival. Fairfax VA: International Association of Fire Chiefs, Safety, Health and Survival Section http://websites.firecompanies.com/iafcsafety/files/2013/10/Rules_of_Engagement_short_v10_2.12.pdf Date accessed: June 2016.

IFSTA [2008]. Essentials of fire fighting. 5th ed. Stillwater, OK: Fire Protection Publications, International Fire Service Training Association.

ISFSI [2013]. International Society of Fire Service Instructors position statement - fire dynamic research in tactical operations. Press release, October. Centerville, VA. International Society of Fire Service Instructors.

LAFD [2011]. Los Angeles Fire Department command post training. 2011 ed. Los Angeles, CA: Los Angeles Fire Department.

Modern Fire Behavior [2014]. S.L.I.C.E. - R.S. Northbrook, IL: UL Firefighter Safety Research Institute [http://modernfirebehavior.com/s-l-i-c-e-r-s/ ]. Date accessed: April 2016.

Mullane M [2009]. Stopping normalization of deviance: A safety program.

[http://mikemullane.com/stopping-normalization-of-deviance/]. Date accessed: April 2016.

NFFF [2004]. \#4 Empowerment. National Fallen Firefighters Foundations 16 Life Safety Initiatives. http://www.everyonegoeshome.com/16-initiatives/4-empowerment/ . Date accessed: April 2016.

NFPA [2008]. Fire fighter fatalities in the United States - 2008. Quincy, MA: National Fire Protection Association. 


\section{Career Fire Apparatus Operator Died After Falling Down an Unsecured Elevator Shaft at a 5-Story Residential Apartment Building - Ohio}

NFPA [2014]. NFPA 1002 Standard for fire apparatus driver/operator professional qualifications. 2014 ed. Quincy, MA: National Fire Protection Association.

NFPA [2013]. NFPA 1500 standard on fire department occupational safety and health program. 2013 ed. Quincy, MA: National Fire Protection Association.

NFPA. [2014]. NFPA 1561: Standard on emergency services incident management system and command safety. 2014 ed. Quincy, MA: National Fire Protection Association.

NFPA [2016]. NFPA 1710: Standard for the organization and deployment of fire suppression operations, emergency medical operations, and special operations to the public by career fire departments. 2016 ed. Quincy, MA: National Fire Protection Association.

NIOSH [2009a]. Nine career fire fighters die in rapid fire progression at commercial furniture showroom - South Carolina. Morgantown, WV: U.S. Department of Health and Human Services, Centers for Disease Control and Prevention, National Institute for Occupational Safety and Health, FACE Report F2007-18 [http://www.cdc.gov/niosh/fire/pdfs/face200718.pdf].

NIOSH [2009b]. Two Career Fire Fighters Die and Captain is Burned When Trapped during Fire Suppression Operations at a Millwork Facility - North Carolina. Morgantown, WV: U.S. Department of Health and Human Services, Centers for Disease Control and Prevention, National Institute for Occupational Safety and Health, FACE Report F2008-07. [http://www.cdc.gov/niosh/fire/reports/face200807.html].

NIOSH [2011a]. A Career Lieutenant and a Career Fire Fighter Found Unresponsive at a Residential Structure Fire - Connecticut. Morgantown, WV: U.S. Department of Health and Human Services, Centers for Disease Control and Prevention, National Institute for Occupational Safety and Health, FACE Report F2010-18. [http://www.cdc.gov/niosh/fire/reports/face201018.html].

NIOSH [2011b]. Two Career Fire Fighters Die and 19 Injured in Roof Collapse during Rubbish Fire at an Abandoned Commercial Structure - Illinois. Morgantown, WV: U.S. Department of Health and Human Services, Centers for Disease Control and Prevention, National Institute for Occupational Safety and Health, FACE Report F2010-38. [http://www.cdc.gov/niosh/fire/reports/face201038.html].

NIOSH [2012]. Volunteer fire fighter caught in a rapid fire event during unprotected search, dies after facepiece lens melts - Maryland. Morgantown, WV: U.S. Department of Health and Human Services, Centers for Disease Control and Prevention, National Institute for Occupational Safety and Health, FACE Report F2011-02 [http://www.cdc.gov/niosh/fire/pdfs/face201102.pdf].

NIOSH [2013]. Career captain sustains injuries at a 21/2 story apartment fire then dies at hospital Illinois. Morgantown, WV: U.S. Department of Health and Human Services, Centers for Disease Control and Prevention, National Institute for Occupational Safety and Health, FACE Report F2012-28 [http://www.cdc.gov/niosh/fire/pdfs/face201228.pdf . 


\section{Career Fire Apparatus Operator Died After Falling Down an Unsecured Elevator Shaft at a 5-Story Residential Apartment Building - Ohio}

NIST [2010]. Report on residential fireground field experiments. Gaithersburg, MD: National Institute of Standards and Technology, NIST Technical Note 1661, April 2010.

[http://www.nist.gov/customcf/get_pdf.cfm?pub_id=904607]. Date accessed: April 2016.

NIST, UL [2013]. Studying fire behavior and fireground tactics. Presentation at the IAFF Redmond Symposium, Denver, CO, August 24, 2013. National Institute for Standards and Technology and Underwriters Laboratories.

USFA [1999]. Special report: Improving firefighter communications. Emmitsburg, MD: U.S. Fire Administration Technical Report SeriesUSFA-TR-099/January 1999.

Weather Underground [2015]. Weather history for Cincinnati OH, March 26, 2015. Atlanta GA: The Weather Channel Interactive, Inc. https://www.wunderground.com/history/airport/KLUK/2015/3/26/DailyHistory.html?req_city=Cincin nati\&req_state $=O H \& r e q \_s t a t e n a m e=\& r e q d b . z i p=45201 \&$ reqdb.magic $=1 \&$ reqdb.wmo=99999

\section{Investigator Information}

This incident was investigated by Timothy R. Merinar, Safety Engineer, and Matt E. Bowyer, General Engineer, with the Fire Fighter Fatality Investigation and Prevention Program, Surveillance and Field Investigations Branch, Division of Safety Research, NIOSH located in Morgantown, WV. An expert technical review was provided by John B. Tippett, Jr., Deputy Fire Chief, Charleston, South Carolina Fire Department. A technical review was also provided by the National Fire Protection Association, Public Fire Protection Division.

\section{Additional Information}

Voice Radio Communications Guide for the Fire Service

The U.S. Fire Administration (USFA) and the International Association of Fire Fighters (IAFF) worked under a cooperative agreement to develop the Voice Radio Communications Guide for the Fire Service as a document to help identify the unique communication needs required by the fire service. This document covers basic radio communication technology, radios and radio systems, portable radio selection and use, trunked radio systems, system design and implementation, interoperability, and other fire service radio communication issues. http://www.iaff.org/08News/PDF/RadioCommunications.pdf

\section{Current Status, Knowledge Gaps, and Research Needs Pertaining to Firefighter Radio Communication Systems}

The National Institute for Occupational Safety and Health (NIOSH) commissioned a study to identify and address specific deficiencies in firefighter radio communications and to identify technologies that may address these deficiencies. Specifically to be addressed were current and emerging technologies that improve, or hold promise to improve, firefighter radio communications and provide firefighter 


\section{Career Fire Apparatus Operator Died After Falling Down an Unsecured Elevator Shaft at a 5-Story Residential Apartment Building - Ohio}

location in structures. This report was prepared under contract with NIOSH. It should not be considered a statement of NIOSH policy or of any agency or individual who was involved. http://www.cdc.gov/niosh/fire/RadComSy.html

\section{Improving Radio Communications}

Several recent incidents involving fire fighter fatalities where inadequate fireground communications were identified as contributing factors to the injuries and deaths prompted the U.S. Fire Administration (USFA) to study the potential causes of communication breakdown and to provide recommendations that would help departments improve operational communications. https://www.usfa.fema.gov/downloads/pdf/publications/tr-099.pdf

\section{Modern Fire Behavior}

This website is meant to serve as a clearinghouse of news and training information related to Modern Fire Behavior and Modern Building Construction Research, Tactics, and Practices along with actual street experiences. http://modernfirebehavior.com/. ModernFireBehavior.com is a joint effort between www.FirefighterCloseCalls.com and the Underwriters Laboratories Fire Safety Research Institute.

\section{IAFC Rules of Engagement for Firefighter Survival}

The international Association of Fire Chiefs (IAFC) is committed to reducing fire fighter fatalities and injuries. As part of that effort, the nearly 1,000 member IAFC Safety, Health and Survival Section has developed the DRAFT “Rules of Engagement for Structural Firefighting” to provide guidance to individual fire fighters and incident commanders, regarding risk and safety issues when operating on the fireground. The intent is to provide a set of "modern procedures" for structural firefighting to be made available by the IAFC to fire departments as a guide for their own standard operating procedure development process. http://www.iafcsafety.org/downloads/Rules_of_Engagement.

\section{IAFF Fire Ground Survival Program}

The purpose of the International Association of Fire Fighters (IAFF) Fire Ground Survival Program is to ensure that training for Mayday prevention and Mayday operations are consistent between all fire fighters, company officers and chief officers. Fire fighters must be trained to perform potentially lifesaving actions if they become lost, disoriented, injured, low on air or trapped. Funded by the IAFF and assisted by a grant from the U.S. Department of Homeland Security through the Assistance to Firefighters (FIRE Act) grant program, this comprehensive fire ground survival training program applies the lessons learned from fire fighter fatality investigations conducted by the National Institute for Occupational Safety and Health (NIOSH) and has been developed by a committee of subject matter experts from the IAFF, the International Association of Fire Chiefs (IAFC) and NIOSH.

http://www.iaff.org/HS/FGS/FGSIndex.htm.

\section{National Institute for Standards and Technology (NIST) - Fire on the Web}

Fire on the Web is a collection of resources from the Building and Fire Research Laboratory's Fire Research Division at NIST. These Web pages provide links to fire related software, experimental fire data and mpeg/quick time movies of fire tests that can be downloaded and/or viewed with a Web browser. http://www.nist.gov/el/fire_research/firesafety/fireontheweb.cfm . 
Career Fire Apparatus Operator Died After Falling Down an Unsecured Elevator Shaft at a 5-Story Residential Apartment Building - Ohio

\section{Underwriters Laboratories (UL) Firefighter Safety Research Institute}

An online course offered by the UL Firefighter Safety Research Institute (FSRI) highlights the tactical application of nearly two decades of research at the National Institute of Standards and Technology (NIST) and UL on how best to fight modern fires. The New York City Fire Department (FDNY), NIST and UL FSRI set fire to abandoned townhouses on Governors Island, New York, in a series of experiments to examine tactics for controlling fires and rescuing occupants inside burning homes in 2012.

http://www.firecompanies.com/modernfirebehavior/governors\%20island\%20online\%20course/story.ht $\underline{\mathrm{ml}}$

\section{Disclaimer}

Mention of any company or product does not constitute endorsement by the National Institute for Occupational Safety and Health (NIOSH). In addition, citations to websites external to NIOSH do not constitute NIOSH endorsement of the sponsoring organizations or their programs or products. Furthermore, NIOSH is not responsible for the content of these websites. All web addresses referenced in this document were accessible as of the publication date. 
Career Fire Apparatus Operator Died After Falling Down an Unsecured Elevator Shaft at a 5-Story Residential Apartment Building - Ohio

\section{Appendix One}

\section{Self-Contained Breathing Apparatus Evaluation}

A summary of the SCBA evaluation by the NIOSH National Personal Protective Technology Laboratory (NPPTL) is attached. Due to their condition, a new facepiece and cylinder were obtained for use during the NIOSH testing. The full NIOSH NPPTL SCBA evaluation report is available upon request. 


\title{
Career Fire Apparatus Operator Died After Falling Down an Unsecured Elevator Shaft at a 5-Story Residential Apartment Building - Ohio
}

\author{
Status Investigation Report of a \\ Self-Contained Breathing Apparatus \\ Submitted By the \\ NIOSH Division of Safety Research for Investigation F2015-06 OH \\ NIOSH Task Number 20231
}

\section{Background}

As part of the National Institute for Occupational Safety and Health (NIOSH) Fire Fighter Fatality

Investigation and Prevention Program, the National Personal Protective Technology Laboratory (NPPTL) agreed to examine and evaluate one SCBA unit identified as a Mine Safety Appliances (MSA) model Firehawk M7, 4500 psi, 60-minute, self-contained breathing apparatus (SCBA).

This SCBA status investigation was assigned NIOSH Task Number 20231. The NIOSH Division of Safety Research (NIOSH/DSR) and the Fire Department were advised that NIOSH NPPTL would provide a written report of the inspections and any applicable test results.

The SCBA unit was hand delivered in a cardboard box to the NIOSH facility in Morgantown, WV on April 24, 2015. The unit was taken to the lower floor of the lab, room 1513, for secured storage. The SCBA unit was then removed for inspection on May 18, 2015 and was placed back into secured storage in room 1513 until the evaluation on May 22, 2015.

\section{SCBA Inspection}

The unit was removed from the packaging in the lower floor of the lab, room 1513, May 1, 2015 by Jay Tarley, Physical Scientist, and, Mike Commodore, Engineering Technician, NPPTL. The SCBA was identified as the Fire Department SCBA and was extensively examined, component by component, in the condition received to determine the conformance of the unit to the NIOSH-approved configuration. The unit was identified as the MSA model Firehawk M7, 60 minute, 4500 psi unit, NIOSH approval numbers TC-13F-500CBRN. The visual inspection process was documented photographically.

The complete SCBA inspection is summarized in Appendix I of the NPPTL report. The condition of each major component of the SCBA that were photographed with a digital camera is contained in Appendix III.

\section{SCBA Testing}

The purpose of the testing was to determine the conformance of each SCBA to the approval performance requirements of Title 42, Code of Federal Regulations, Part 84 (42 CFR 84). Further testing was conducted to provide an indication of the conformance of each SCBA to the National Fire Protection Association (NFPA) Air Flow Performance requirements of NFPA 1981, Standard on Open-Circuit Self-Contained Breathing Apparatus for the Fire Service, 1997 Edition.

NIOSH SCBA Certification Tests (in accordance with the performance requirements of 42 CFR 84):

1. Positive Pressure Test [§ 84.70(a)(2)(ii)] 


\section{Career Fire Apparatus Operator Died After Falling Down an Unsecured Elevator Shaft at a 5-Story Residential Apartment Building - Ohio}

2. Rated Service Time Test (duration) [§ 84.95]

3. Static Pressure Test [§ 84.91(d)]

4. Gas Flow Test [§ 84.93]

5. Exhalation Resistance Test [§ 84.91(c)]

6. Remaining Service Life Indicator Test (low-air alarm) [§ 84.83(f)]

National Fire Protection Association (NFPA) Tests (in accordance with NFPA 1981, 1997 Edition): 7. Air Flow Performance Test [Chapter 5, 5-1.1]

Appendix II of the NPPTL report contains the complete NIOSH test report for the SCBA. Tables ONE, TWO, THREE and FOUR summarize the NIOSH and NFPA test results.

\section{Summary and Conclusions}

A SCBA unit was submitted to NIOSH/NPPTL by the NIOSH/DSR for evaluation as part of FFFIPP investigation F2015-06 OH. The SCBA unit was delivered to NIOSH on April 24, 2015 and extensively inspected on May 18, 2015. The unit was identified as a MSA model Firehawk M7, 4500 psi, 60-minute, SCBA (NIOSH approval numbers, TC-13F-500CBRN). The unit didn't show any signs of heat damage but exhibited signs of physical damage likely from the fall and/or extrication efforts. The cylinder valve, as received, was in the off position. The cylinder gauges showed that the tank was empty. The facepiece was included and the regulator housing was dislodged from the mask. The entire unit was in good overall condition. The NFPA approval label was present and readable. The personal alert safety system (PASS) did not function.

This SCBA met the requirements of the NIOSH Positive Pressure Test, as the unit did maintain a positive pressure for the 60 minute minimum duration of the unit. The unit passed all of the other NIOSH tests.

The SCBA unit was returned to storage pending return to the Fire Department.

If this unit is to be placed back in service, the SCBA must be repaired, tested, cleaned and any damaged components replaced and inspected by a qualified service technician, including such testing and other maintenance activities as prescribed by the schedule from the SCBA manufacturer. Typically a flow test is required on at least an annual basis.

The complete NIOSH NPPTL SCBA evaluation report for TN-20231 is available upon request. 